\title{
Moral Distress and Avoidance Behavior in Nurses Working in Critical Care and Non-Critical Care Units
}

Mary Jo De Villers

Loyola University Chicago

Follow this and additional works at: https://ecommons.luc.edu/luc_diss

Part of the Nursing Commons

\section{Recommended Citation}

De Villers, Mary Jo, "Moral Distress and Avoidance Behavior in Nurses Working in Critical Care and NonCritical Care Units" (2010). Dissertations. 195.

https://ecommons.luc.edu/luc_diss/195

This Dissertation is brought to you for free and open access by the Theses and Dissertations at Loyola eCommons. It has been accepted for inclusion in Dissertations by an authorized administrator of Loyola eCommons. For more information, please contact ecommons@luc.edu. (c) (i) (9)

This work is licensed under a Creative Commons Attribution-Noncommercial-No Derivative Works 3.0 License. Copyright @ 2010 Mary Jo De Villers 
LOYOLA UNIVERSITY CHICAGO

MORAL DISTRESS AND AVOIDANCE BEHAVIOR IN NURSES WORKING IN CRITICAL CARE AND NON-CRITICAL CARE UNITS

\author{
A DISSERTATION SUBMITTED TO \\ THE FACULTY OF THE GRADUATE SCHOOL \\ IN CANDIDACY FOR THE DEGREE OF \\ DOCTOR OF PHILOSOPHY
}

PROGRAM IN NURSING

BY

MARY JO DE VILLERS

CHICAGO, ILLINOIS

DECEMBER 2010 
Copyright by Mary Jo De Villers, 2010 All rights reserved. 


\section{ACKNOWLEDGEMENTS}

Dr. Holli DeVon, Committee Chair, thank you for your support, encouragement, and guidance throughout the dissertation process. You have been an excellent role model and mentor.

Dr. Beverly Kopala, Advisor and Committee Member, thank you for your guidance as I progressed through the nursing program and for sharing your knowledge of ethics and moral distress.

Dr. Karen Saban, Committee Member, thank you for the insightful feedback and suggestions for further analyses that improved the final product.

Dr. Lisa Burkhart, thank you for your participation on my preliminary exam committee and for sharing your expert knowledge of spirituality.

Dr. Karen Egenes, thank you for your participation on my preliminary exam committee and for sharing your classroom during my teaching practicum.

Dr. Mary Corley, thank you for sharing your instrument and dedication to the topic of moral distress in nursing. Your work has been inspirational and provided a foundation for this work and that to come in the future.

To my colleagues in the Summer Cohort, thank you for sharing your knowledge, your time, and your aspirations with me. You have been a source of inspiration and support from the very beginning and truly know the challenges and growth experiences that took place along the way. You are treasured. 
To the faculty and staff of the Program in Professional Nursing at the University of Wisconsin, Green Bay, thank you for your support and encouragement over the years. Your collegiality has been invaluable.

A special heartfelt thank you to my family for their never-ceasing patience and understanding. You have seen me through this journey and share in its accomplishment. 
TABLE OF CONTENTS

ACKNOWLEDGEMENTS

LIST OF TABLES $\quad$ ix

LIST OF FIGURES $\quad$ X

ABSTRACT $\quad$ xi

CHAPTER ONE: INTRODUCTION

Moral Distress 1

Definitions of Moral Distress $\quad 1$

Effects of Moral Distress

Significance of Moral Distress to the Nursing Profession 5

Who Experiences Moral Distress $\quad 8$

Justification and Purpose of the Study $\quad 8$

Aims and Hypotheses $\quad 9$

CHAPTER TWO: LITERATURE REVIEW

Moral Distress $\quad 11$

Moral Distress in Nursing and Nursing Practice $\quad 11$

Corley's Model of Nurses' Moral Distress 11

Quantitative Methods $\quad 18$

Qualitative Methods $\quad 22$

Mixed Methods $\quad 25$

Interdisciplinary Studies $\quad 28$

Other Models of Moral Distress $\quad 30$

Wilkinson's Moral Distress Model 30

Model of Military Nursing Moral Distress

Avoidance Thoughts and Behaviors $\quad 32$

Limitations of Previous Studies $\quad 35$

Sample Size $\quad 35$

Lack of Clarity in Directions for Completing Instruments 38

$\begin{array}{ll}\text { Single Exemplar } & 38\end{array}$

Other Limitations $\quad 38$

Summary of the Literature $\quad 38$

Conceptualization of Moral Distress $\quad 38$

Empirical Evidence of Moral Distress $\quad 40$

Gaps in Knowledge $\quad 42$

Practice Settings $\quad 42$

Retention of Professional Nurses $\quad 42$

Homogeneity of Sample Populations $\quad 43$

Measurement of Moral Distress 43 
CHAPTER THREE: METHODS

Review of the Study Purpose $\quad 45$

Aims and Hypotheses $\quad 46$

Design $\quad 47$

$\begin{array}{ll}\text { Power Analyses } & 48\end{array}$

$\begin{array}{ll}\text { Sample } & 48\end{array}$

$\begin{array}{ll}\text { Setting } & 49\end{array}$

Measurement Instruments 49

Moral Distress Scale (MDS) $\quad 49$

Psychometric properties $\quad 51$

Overview of modifications/revisions $\quad 51$

Impact of Event Scale (IES)

Psychometric properties $\quad 52$

Demographic Data Form $\quad 54$

Data Collection Procedures $\quad 54$

Statistical Analyses $\quad 55$

Data Preparation and Screening $\quad 55$

Human Subjects Protection $\quad 56$

Potential Benefits of the Proposed Research to the Participants and Others 57

$\begin{array}{ll}\text { Inclusion of Women and Minorities } & 57\end{array}$

CHAPTER FOUR: RESULTS

Data Analysis $\quad 59$

Data Preparation $\quad 60$

$\begin{array}{ll}\text { Data Entry } & 60\end{array}$

$\begin{array}{ll}\text { Missing Data } & 60\end{array}$

$\begin{array}{ll}\text { Normality } & 61\end{array}$

Linearity $\quad 61$

Homoscedasticity $\quad 62$

Sample Characteristics and Demographic Data $\quad 62$

$\begin{array}{ll}\text { Sampling Information } & 62\end{array}$

Demographic Data $\quad 63$

Reliability and Validity of the MDS $\quad 68$

$\begin{array}{ll}\text { Reliability of the MDS } & 68\end{array}$

Validity of the MDS $\quad 69$

Reliability and Validity of the IES $\quad 69$

Reliability of the IES $\quad 69$

Validity of the IES $\quad 69$

Alpha Level, Power, and Effect Size $\quad 70$

Moral Distress and Avoidance Behavior in Nurses Working in Critical Care and $\begin{array}{ll}\text { non-Critical Care Settings } & 70\end{array}$ $\begin{array}{ll}\text { Aim 1a } & 70\end{array}$ 
Differences in moral distress scores across groups $\quad 71$

Aim 1b 73

Difference in moral distress and avoidance scores across groups $\quad 73$

Difference in moral distress and avoidance scores across groups after $\begin{array}{ll}\text { adjusting for age } & 74\end{array}$

Aim $2 \quad 75$

Correlation between moral distress and avoidance thoughts and
behaviors

$\begin{array}{ll}\text { Identification of a stressor event } & 75\end{array}$

Differences in IES scores across groups $\quad 76$

$\begin{array}{ll}\text { Aim } 3 & 78\end{array}$

$\begin{array}{ll}\text { Difference between MDS and IES after adjusting for age } & 78\end{array}$

$\begin{array}{ll}\text { Summary of Findings } & 78\end{array}$

CHAPTER FIVE: DISCUSSION $\quad 80$

Aims of the Study $\quad 80$

Aim 1a: Differences in MDS Scores $\quad 80$

Aim 1b: Differences in IES Scores $\quad 81$

Aim 2: Correlation Between Moral Distress and Avoidance Thoughts
and Behaviors

Aim 3: Relationship Between Moral Distress and Avoidance Thoughts and

Behaviors After Adjusting for Age $\quad 83$

$\begin{array}{ll}\text { Lack of Power } & 83\end{array}$

Disproportionate Number of Critical Care Nurses $\quad 84$

Small Effect Sizes $\quad 85$

Reliability and Validity of the MDS and IES $\quad 86$

Implications for Nursing $\quad 86$

$\begin{array}{ll}\text { Strengths of the Study } & 88\end{array}$

Limitations of the Study $\quad 89$

Recommendations for Future Research $\quad 90$

Summary of the Discussion $\quad 91$

APPENDIX A: MORAL DISTRESS SCALE 93

APPENDIX B: IMPACT OF EVENT SCALE 97

APPENDIX C: DEMOGRAPHIC DATA FORM 99

APPENDIX D: PERMISSIONS 102

$\begin{array}{ll}\text { REFERENCES } & 105\end{array}$

$\begin{array}{ll}\text { VITA } & 113\end{array}$ 


\section{LIST OF TABLES}

Table

1. Concepts Relevant to Moral Distress 14

2. Variables and Measures $\quad 47$

3. Psychometrics of the Moral Distress Scale 53

4. Comparison of Gender and Racial/Ethnic Characteristics of Sample Participants to US Population of Nurses $\quad 64$

5. Demographic Characteristics for Participants Completing the MDS Only 65

6. Demographic Data for Critical Care and Non-Critical Care Nurses 66

7. Reliability Coefficients for the MDS and IES in this Study 68

8. Stressor Life Events and Times Identified on IES 76 


\section{LIST OF FIGURES}

\section{Figure}

1. Corley's Model for a Theory of Moral Distress 


\begin{abstract}
Significance: Nurses facing impediments to what they perceive as moral practice may experience inner turmoil, frustration, and moral distress. These scenarios may culminate in resignation from employment at the individual level, increased attrition at the systems level, and poor patient outcomes, including increased morbidity and mortality. Moral dilemmas challenge nurses in a variety of practice settings and, although nurses have taken on expanded roles in their practice, factors beyond the nurse's control may hinder their ability to act as moral agents for patients and families.
\end{abstract}

Purpose: To explore the relationships between moral distress and avoidance thoughts and behavior between nurses currently practicing in critical care and non-critical care settings.

Methods. A descriptive cross-sectional comparative design was used. A randomized subset $(n=370)$ of critical care nurses was drawn from a random sample of members of the American Association of Critical-Care Nurses. The remainder of the participants were drawn from convenience samples of 87 nurses from the Rural Nurse Managers Organization and two nursing programs in the Midwest $(n=225)$. Participants worked in critical care as well as non-critical care settings in the United States. Online surveys, using Qualtrics software, and paper and pencil surveys were used for data collection. The Moral Distress Scale (MDS) and Impact of Event Scale (IES) were used to measure the variables of interest. Demographic data were analyzed with descriptive 
statistics including frequencies, t-tests, and chi-square. Multivariate analysis of variance was used to examine differences between groups in moral distress, avoidance behaviors, and age. Linear regression was used to examine relationships between MDS and IES scores by groups of nurses after adjusting for age.

Results: Critical care nurses were significantly older than non-critical care nurses $(t=3.18, \mathrm{p}=.002)$ with mean ages of 43 and 35 respectively. Moral distress scores were higher for critical care nurses compared to non-critical care nurses, but the difference was not statistically significant $(t(94)=1.31, p=0.25)$. Critical care nurses reported higher levels of moral distress intensity and frequency, but there was no statistically significant difference $(F(2,93)=.90, p=.41) .3)$ There was also no significant difference between critical care and non-critical care nurses on Moral Distress Scale and Impact of Events Scale scores $(F(2,93)=2.19, \mathrm{p}=.12)$. After adjusting for age, there was no significant difference between critical care nurses and non-critical care nurses on Moral Distress Scale $(F(1,92)=.892, p=.347)$ and Impact of Events Scale scores $(F(1,92)=3.801, p=$ .054). There was an extremely small positive correlation between moral distress and avoidance $(r=0.107, n=96, p=.298)$.

Discussion: Moral distress is present in both critical care and non-critical care nurses. Knowing that nurses do experience moral distress is a concern for both nurses providing direct patient care and administrators. If nurses are avoiding patients due to moral distress, the well-being of the patients and nurse may be compromised. It is important that those responsible for recruiting and retaining nurses are aware of the presence of moral distress and avoidance as part of nursing practice and that they develop strategies to help nurses manage its effects. This study increased knowledge of moral 
distress and avoidance behavior in nursing practice. Occurrences of moral distress that nurses experienced most frequently and with the most intensity were identified, as well as the frequency and context of self-identified stressful life events associated with avoidance behavior. 


\section{CHAPTER ONE}

\section{INTRODUCTION}

The focus of this research was on exploring the relationships between moral distress and avoidance behavior between nurses currently practicing in critical care and non-critical care settings. Moral dilemmas challenge nurses in a variety of practice settings and, although they have taken on expanded roles and a more participative nature in their practice, factors beyond the nurse's control may hinder their ability to act as moral agents for patients and families. When nurses face impediments to what they perceive as moral practice, they may experience the inner turmoil and frustration of moral distress. Avoidance involves an individual's physical or psychosocial expressions directed at avoiding, or thinking about, reminders of a given event. The goal of the study was to contribute to an understanding of moral distress and its relationship to nurse avoidance behavior, as well as to provide a foundation for future research to identify strategies to prevent attrition and resignation of nurses and poor patient outcomes that may result from its occurrence.

\section{Moral Distress}

\section{Definitions of Moral Distress}

The earliest work found in the literature addressing moral distress defined it as a psychological disequilibrium resulting from knowing the ethical action to take but not taking it due to an inhibiting medical power structure or institutional policy (Jameton, 
1984). Similarly, Wilkinson (1987/88) addressed moral distress as a sensory event - a "negative feeling state experienced when a person makes a moral decision but does not follow through by performing the moral behavior indicated by that decision" (p. 16). Physical symptoms reported by nurses in Wilkinson's study included heart palpitations, diarrhea, and headache.

Fenton (1988) identified moral distress as a disturbing emotional response occurring when one's personal beliefs about right and wrong are violated. Corley (2002) drew from Jameton's work in defining the concept of moral distress as psychological disequilibrium, negative feeling state, and the suffering that nurses experience when they do not act on moral decisions due to institutional constraints.

Hanna $(2004,2005)$ defined moral distress as an act of interior aversion in response to a perceived harm to a known good (moral end) and involving a perceived violation of the person. Even if the violation is not articulated, moral distress can result in a disconnection from self and others. Interior aversion is a withdrawal from the perceived source of the harm and originates with a pre-cognitive perception the author identifies as visceral discernment. Although visceral discernment may preclude conscious recognition of initial awareness of moral distress, it may initiate behaviors and symptoms of the phenomenon.

Reviewing the literature from 1980 to February 2007 on the effects of unresolved moral distress on nurse turnover, and reflecting on the earlier work of Wilkinson (1987/1988), Australian investigators Schluter, Winch, Holzhauser, and Henderson 
(2008) define the concept of moral distress as "an emotion that is expressed when the moral complexity of a situation is not leading to a resolution, thereby having the potential to cause harm to the individual nurse" (p. 306). This definition acknowledges that moral distress is complex and holds the potential for harming nurses. It is the absence of resolution that results in the lingering nature of the distress.

While acknowledging Jameton's definition of moral distress, Tiedje (2000) refines the concept of moral distress as a process: recognizing that a decision is difficult to act upon; experiencing emotional distress; reflecting on the situation; choosing from possible strategies for resolution; and taking action. This process moves beyond identification of the phenomenon to the cognitive and behavioral elements that can lead to individual or collective moral action towards resolution of a morally-charged situation. Synthesizing these earlier works, Nathaniel (2002) offers the following definition of moral distress:

Moral distress is the pain or anguish affecting the mind, body or relationships in response to a situation in which the person is aware of a moral problem, acknowledges moral responsibility, and makes a moral judgment about the correct action; yet, as a result of real or perceived constraints, participates in perceived moral wrongdoing (p. 5).

\section{Effects of Moral Distress}

Effects of moral distress include loss of self-worth, interference with personal relationships, psychological effects (depression), behavioral (nightmares, crying), and physical symptoms such as heart palpitations, diarrhea, and headache. Elpern, Covert, and Kleinpell (2005) report feelings of powerlessness, hopelessness, and lack of support. 
Additionally, Austin, Lemermeyer, Goldberg, Bergum, and Johnson (2005a) report anger, nausea, frustration, grief, misery, and ineffectiveness.

Moral distress is not only a situational phenomenon, but holds the potential for long-term residual effects when moral distress is sustained. Hardingham (2004) describes a practice experience where she did not have the courage to act with integrity in a patient care situation. She relates that the experience remains with her and posits that while sustained moral distress can threaten one's integrity, it can also provoke clarification of moral and philosophical commitments through dialogue with others about situations in which moral compromise has occurred. In this sense, moral distress may present as a growth experience and one that provides insight for nurses to understand and accommodate to its presence as an element of professional nursing practice. Webster and Baylis (2000) address the grievous nature of sustained moral distress and suggest that persons carry it with them from life events in which they compromised themselves when faced with moral distress, and that these times are painful because they betray cherished beliefs and values:

The experience ...can sear the heart. The passage of time may blunt the acute distress, the profound uncertainty and fear, the guilt, and the remorse, but our experience suggests that people who have lived through serious moral compromise carry the remnants of the experience for many years, if not a lifetime. (p. 223)

Moral distress in nursing has been reported as a significant factor in burnout, resignation, and attrition. Taylor (2002) suggests that repeated moral distress leads to withdrawal and a flight response on the part of nurses to other jobs. Nurses may become apathetic leading to clinical mistakes in the practice setting. Peter and Liaschenko (2004) 
consider moral distress and the effect of proximity to patients on nurses' moral responsiveness. The authors posit that moral distress has "appeared with increasing, even alarming regularity in the nursing ethics literature" (p. 218) and that there is a correlation between moral distress and the unacceptable conditions under which nurses practice. Loss of self-worth, impaired sense of wholeness, depression, and intent to leave the profession, along with behavioral and other physical symptoms have been reported. Quality of patient care is threatened as nurses avoid patients and/or situations as a coping strategy for dealing with moral distress (Wilkinson, 1987/1988).

Much has been learned from prior investigations of the consequences of moral distress for nurses and their patients. In previous studies, the experience has taken on different meanings dependent on the context of the situation, organizational environment, experience of the staff, and beliefs and values of persons involved in ethical decisionmaking. Investigators have expanded the meaning of the concept and further clarified the depth and breadth of physical and psychological consequences. Definitions have varied from knowing the morally correct action to take, but being constrained from taking that action (Jameton, 1993), to a sense of disconnection from self and others and an interior aversion with perceived violation of the person (Hanna, 2004, 2005). Nurses repeatedly facing these situations may leave the profession in an effort to maintain psychosocial integrity.

\section{Significance of Moral Distress to the Nursing Profession}

Nurses facing repeated situations that result in the experience of moral distress may become unable or unwilling to continue to practice in a profession that already faces 
a shortage of practitioners. Buchan and Aiken (2008) suggest that the current shortage is not necessarily a shortage of qualified nurses, but a shortage of nurses who are willing to work in the present conditions, including insufficient staffing, inappropriate skill mix, and inadequate support. These issues have been associated with the experience of moral distress. This erosion of the nurse workforce has significant implications for the health and well-being of patient populations, as well as the nurse caregivers and their families. Moral distress can result in psychological disintegration of persons (Austin, Rankel, Kagan, Bergum, \& Lemermeyer, 2005b; Gutierrez, 2005; Hanna, 2004,2005; Kain, 2007; Rushton, 2006; Wilkinson, 1987/1988), attrition (Brosche, 2007; Gutierrez, 2005; Hamric, \& Blackhall, 2007; Laabs, 2005; Schluter et al., 2008), resignation (Brosche, 2007; Hamric, \& Blackhall, 2007; Janvier, Nadeau, Deschênes, Couture, \& Barrington, 2007; Kain, 2007; Schluter et al., 2008; Wilkinson, 1987/1988), and poor patient outcomes (Brosche, 2007; Corley, Minick, Elswick, \& Jacobs, 2005; Gutierrez, 2005; O’Haire, \& Blackford, 2005; Schluter et al., 2008; Sundin-Huard, \& Fahy,1999; Zuzelo, 2007).

Nurses are the single largest group of health care providers and the void they leave in exiting the profession negatively impacts the quality and quantity of patient care. The failure to effectively cope with moral distress can lead to apathy, avoidance of patients and situations that evoke moral distress and burnout. Increased patient morbidity and, in some instances, mortality may result. Studies show that nurses most unable to cope with moral distress and likely to leave the profession may be the best patient advocates and have the highest levels of moral sensitivity (Tiedje, 2000; Wilkinson, 
1987/1988). Millette (1993) advises the importance of identifying those health care providers who are at risk for moral distress. In examining orientations toward moral reasoning, she found that nurses who used a 'caring' approach with an emphasis on relationships and personal connections rather than 'principles' and 'rules' to make moral decisions were more likely to exit the profession. These findings hold significant implications for managers, supervisors, and colleagues in identifying those nurses at risk for moral distress.

Hanna's (2005) work contributed to the knowledge of moral distress by delineating different types of moral distress and the concept of interior aversion which holds significant implications for the provision of quality patient care by distancing the nurse from the care recipient. Moral distress is observed as possessing five properties: perception, pain, valuing, altered participation, and perspective. Three types of moral distress are identified: shocked (declared), muted, and suppressed (persistent). Shocked (declared) moral distress is abrupt and intensely experienced with the initial perception of harm. Muted moral distress is an interior experience, but reflects an exterior silence and includes headache, nausea, and fatigue. Suppressed (persistent) moral distress blocks reflective self-reflection related to the experience and results in fatigue, depression, migraine headaches, and gastrointestinal upset. The physiological basis of this moral distress phenomenon may be linked with Lieberman's (2000) identification of neurotransmitters in the basal ganglia of the brain as a source of emotional appraisal, evaluation, and decision making regardless of conscious awareness. Additionally, Hanna (2005) describes the element of evolving moral distress, which develops over time as a 
person speaks out with greater force and to larger groups to attempt to right the wrong they believe exists.

\section{Who Experiences Moral Distress}

While most studies on moral distress were conducted in critical care areas, nurses working with elderly persons in long-term care have been found to be at risk for moral distress as well. This occurs due to a shortage of nurse care providers, mandatory overtime, unmanageable workloads, lack of nurse-physician collaboration, and institutional constraints. With the increasing aging population, Pijl-Zieber et al. (2008) suggest that nurses and other healthcare professionals working with older patients may need to become increasingly proactive in safeguarding against the development of moral distress.

\section{Justification and Purpose of the Study}

The rationale for conducting the study was related to the negative consequences moral distress can have on nurses, patients, families, and health care institutions; attrition of nurses who are unable to successfully cope with moral distress; negative patient outcomes including morbidity and mortality as a result of avoidance behavior; and high costs of orientation programs. In 2003, Lee reported the cost of replacing a nurse was 150 percent of their annual wage. For example, the cost of replacing a nurse making $\$ 50,000$ a year was $\$ 75,000$. Gardner, Babin, Romero, Trull, and Turpin (2009) report the cost for recruiting and replacing an $\mathrm{RN}$ to be approximately \$40,000. Bratt (2009) estimates the cost of replacing a nurse is equal to their annual salary, which is $\$ 62,140$ for Wisconsin nurses. Jones (2004) identifies five consequences of nurse turnover for healthcare 
organizations that nurse executives and administrators must consider, 1) loss of future returns that would have accrued from past investments in nurses had they remained in their positions, 2) short-term productivity losses and workforce instability, 3) costs of temporary staffing, patients deferred to other units, or employed nurses working overtime to fill vacancies, 4) investments necessary to orient and train new nurses, and 5) difficulty finding nurse replacements resulting in unsafe patient-nurse ratio with decreased quality of care and nurses who are overburdened and burned out. Clearly, situations that result in nurses leaving the workforce significantly challenge financial stability in health care institutions. Therefore, the purpose of this study was to examine moral distress and avoidance in critical care and non-critical care nurses.

\section{Aims and Hypotheses}

Aim 1a. To determine if there is a difference between the intensity and frequency of moral distress of nurses in critical care and non-critical care settings.

Hypothesis 1a. The intensity and frequency of moral distress is greater in critical care nurses compared to non-critical care nurses.

Aim 1b. To determine if there is a difference in mean Moral Distress Scale and Impact of Event Scale scores between critical care and non-critical care nurses and to determine if there was a difference after adjusting for age.

Hypothesis $1 \mathrm{~b}$. There is no difference between moral distress and avoidance behaviors of nurses in critical care and non-critical care settings.

Aim 2. To determine if there is a correlation between moral distress and avoidance behaviors in critical care and non-critical care nurses. 
Hypothesis 2. There is a positive correlation between moral distress and avoidance thoughts and behaviors.

Aim 3. To determine if there is a relationship between moral distress and avoidance behaviors in critical care and non-critical care nurses adjusting for age.

Hypothesis 3 . There is no difference between moral distress and avoidance behaviors by nurses after adjusting for age. 


\section{CHAPTER TWO}

\section{LITERATURE REVIEW}

The purpose of this study was to examine moral distress and avoidance in critical care and non-critical care nurses. The review of the literature is organized around the concept of moral distress and the factors hypothesized to be associated with moral distress.

\section{Moral Distress}

\section{Moral Distress in Nursing and Nursing Practice}

In the past 20 years, moral distress has been recognized as more prevalent in nurses working in intensive care settings, and there is greater awareness of the influence of environment on its prevalence. Nurses practicing in intensive care units are at higher risk for moral distress due to the nature of patient conditions and related ethical issues arising in these settings (e.g., end-of-life decision-making, autonomy, allocation of scarce resources, quality vs. quantity of life). Thus, the majority of studies on moral distress have been done with nurses working in intensive care units. Sixteen studies examining moral distress in the patient care setting were identified. Studies are reported by research methodology for ease of interpretation.

\section{Corley's Model of Nurses' Moral Distress}

The conceptual framework for this study is derived from the work of Corley (2002) author of the Moral Distress Scale (MDS). The MDS was used to operationalize 
moral distress in this study. This model was chosen as it draws from the work of earlier moral distress studies and enhances earlier frameworks with the addition of concepts related to moral distress. For this study, the concept of avoidance is added to the framework as it is hypothesized from prior studies that avoidance is associated with moral distress (Hanna, 2005; Röndahl, Innala, \& Carlsson, 2003). Avoidance is more than the absence of physical presence. It is conscious efforts to avoid thinking about an event or reminders of an event (Hogan \& Schmidt, 2002).

Corley (2002) views nursing as a moral endeavor and draws on the work of Wilkinson (1987/88) and Jameton $(1984,1993)$ in defining moral distress. Jameton (1993) focuses on the initial distress that is experienced involving feelings of frustration, anger, and anxiety people experience when faced with institutional obstacles and conflict with others about values. In discussing moral distress in nursing practice, Wilkinson defines it as the psychological disequilibrium and negative feeling state experienced when a person makes a moral decision but does not follow through by performing the moral behavior indicated by that decision. Corley's (2002) theory of moral distress proposes what happens when a nurse either is unable or feels unable to advocate for a patient. Moral distress is set in an external and internal context: the external context is the work environment; the internal context is the nurses' psychological responses. Moral concepts relevant to the theory can be seen from the individual's perspective and that of the organization. The theory acknowledges institutional constraints as a major component and suggests that the context for justifying ethical choices should not exclude the context within which decisions are made. 
Corley's theory is based on two premises; 1) nursing is a moral profession, and 2) nurses are moral agents. When a nurse cannot enact moral agency, she/he becomes vulnerable to moral distress. Corley proposes there are moral concepts that impact the development of moral competency which is necessary for moral action. Definitions of moral concepts which are related to both nursing as a moral profession and to nurses as moral agents are shown in Table 1. A visual representation of Corley's theory of moral distress that incorporates these concepts is shown in Figure 1. The concepts of commitment, sensitivity, autonomy, sense-making, judgment, conflict, and certainty are interrelated with moral competency and moral distress. The development of moral competency will depend on how the nurse has incorporated the other concepts into her value system and lead to a decision to act (adherence to moral values) or to moral distress if the nurse chooses not to act or if she feels she cannot act due to institutional constraints.

Corley draws from the work of Rest (1986) in defining moral competency as the ability to make moral sense of situations, use good moral judgment and intention, and engage in morally appropriate behavior. Moral competency is fostered by moral commitment, moral sensitivity, and moral imagination. The more morally committed and morally competent a nurse is, the greater the moral comfort she will experience and the less moral distress. This in turn facilitates her ability to advocate for the patient. Moral sensitivity fosters commitment to patients and the ability to use strategies in ethical decision-making. Nurses who have lost their ability to care may lack moral sensitivity and will not experience moral distress. Those who maintain high levels of sensitivity and 
competency are more likely to demonstrate moral courage and moral heroism and are able to take action resulting in moral comfort rather than moral distress. The nurse's ability to act with moral courage and comportment are contingent on the interaction, absence, or presence of the moral concepts within the model (Corley, 2002).

Table 1

Concepts Relevant to Moral Distress

\begin{tabular}{|c|c|c|}
\hline $\begin{array}{c}\text { Moral } \\
\text { Concept }\end{array}$ & Definition & Relationship to Moral Distress \\
\hline Commitment & $\begin{array}{l}\text { Engagement in moral issue } \\
\text { Loyalty to values } \\
\text { Willingness to take risks } \\
\text { (Tourtillott, 1982) }\end{array}$ & $\begin{array}{l}\text { High levels foster: } \\
\text { Moral competency } \\
\text { Moral behavior } \\
\downarrow \text { moral distress (Corley, 2002) }\end{array}$ \\
\hline Sensitivity & $\begin{array}{l}\text { Ability to: } \\
\text { Recognize a moral conflict } \\
\text { Understand patient's } \\
\text { vulnerability } \\
\text { Hold insight of ethical } \\
\text { consequences of decision } \\
\text { (Lützén, Johansson, \& } \\
\text { Nordström,2000) }\end{array}$ & $\begin{array}{l}\text { High levels: } \\
\text { Reflect commitment to } \\
\text { patients } \\
\text { Foster development of moral } \\
\text { competency } \\
\downarrow \text { moral distress. } \\
\text { (Oddi, Cassidy, \& Fisher, } \\
\text { 1995) }\end{array}$ \\
\hline Autonomy & $\begin{array}{l}\text { Freedom and responsibility to choose } \\
\text { (Scott, 1998) }\end{array}$ & $\begin{array}{l}\text { High levels } \uparrow \text { moral distress in } \\
\text { absence of moral commitment and } \\
\text { moral competence. (Corley, 2002) }\end{array}$ \\
\hline Sense making & $\begin{array}{l}\text { Structuring of moral meaning } \\
\text { (Rest, 1986) }\end{array}$ & $\begin{array}{l}\text { High levels of moral commitment and } \\
\text { competence foster sense making of } \\
\text { situations and } \downarrow \text { moral distress. } \\
\text { (Corley, 2002) }\end{array}$ \\
\hline Judgment & $\begin{array}{l}\text { Integration of ethical considerations } \\
\text { of a course of action to determine } \\
\text { what ought to be done (Corley, 2002) }\end{array}$ & $\begin{array}{l}\text { Nurses with high levels of moral } \\
\text { commitment, competency, and sense } \\
\text { making more likely to make } \\
\text { appropriate moral judgments and } \\
\text { have } \downarrow \text { moral distress. } \\
\text { (Corley, 2002) }\end{array}$ \\
\hline Conflict & $\begin{array}{l}\text { Situation involving clash of moral } \\
\text { values about a morally right action } \\
\text { (Redman \& Fry, 2000) }\end{array}$ & $\begin{array}{l}\text { Nurses with autonomy, limited } \\
\text { choices, violated values, and } \\
\text { relationships with suffering patients } \\
\text { have more moral conflict. } \\
\text { (Corley, 2002) }\end{array}$ \\
\hline
\end{tabular}


Table 1 (continued)

\begin{tabular}{|c|c|c|}
\hline $\begin{array}{l}\text { Moral } \\
\text { Concept }\end{array}$ & Definition & Relationship to Moral Distress \\
\hline Competency & $\begin{array}{l}\text { Ability to: } \\
\text { Make moral sense of } \\
\text { situations } \\
\text { Use good moral judgment } \\
\text { Engage in moral behavior } \\
\text { (Rest, 1986) }\end{array}$ & $\begin{array}{l}\text { Nurses with moral commitment, but lacking } \\
\text { in moral competency more likely to } \\
\text { experience moral distress. (Corley, 2002) }\end{array}$ \\
\hline Certainty & $\begin{array}{l}\text { Absolute moral conviction that } \\
\text { leads to risk self to act rightly } \\
\text { (Wurzbach, 1996) }\end{array}$ & $\begin{array}{l}\text { Less moral distress when combined with } \\
\text { moral commitment, competence, and } \\
\text { autonomy. (Corley, 2002) }\end{array}$ \\
\hline Imagination & $\begin{array}{l}\text { "Aspect of the imagination } \\
\text { which potentially becomes } \\
\text { active in the moral agent's } \\
\text { attempt to consider what moral } \\
\text { decisions to make" (Scott, } \\
\text { 1998, p. 45) }\end{array}$ & $\begin{array}{l}\text { Fosters high levels of moral sensitivity and } \\
\text { moral competence. } \\
\downarrow \text { moral distress. (Corley, 2002) }\end{array}$ \\
\hline Integrity & $\begin{array}{l}\text { Adherence to moral values; } \\
\text { tied to one's sense of self- } \\
\text { respect. (de Raeve, 1998) }\end{array}$ & $\begin{array}{l}\text { In absence of moral competency may lead to } \\
\text { moral distress. (Kelly, 1998) }\end{array}$ \\
\hline Outrage & $\begin{array}{l}\text { Feelings of anger and shock in } \\
\text { response to a morally charged } \\
\text { situation } \\
\text { 1991) }\end{array}$ & $\begin{array}{l}\text { More likely to occur in the presence of } \\
\text { moral sensitivity, moral commitment and } \\
\text { moral competence; less moral distress. } \\
\text { (Corley, 2002) }\end{array}$ \\
\hline Courage & $\begin{array}{l}\text { Willingness to take a stand } \\
\text { amidst controversy or } \\
\text { challenge, despite potential } \\
\text { jeopardy to job (Pike, } 1991)\end{array}$ & $\begin{array}{l}\text { Combined with action } \downarrow \text { moral distress. } \\
\text { (Corley, 2002) }\end{array}$ \\
\hline Heroism & $\begin{array}{l}\text { Ability to act as result of moral } \\
\text { courage. (Corley, 2002) }\end{array}$ & Absence $\uparrow$ moral distress (Corley, 2002) \\
\hline Comfort & $\begin{array}{l}\text { Opposite of moral distress } \\
\text { (Corley, 2002) }\end{array}$ & $\begin{array}{l}\text { Result of morally appropriate action } \\
\text { (Corley, 2002) }\end{array}$ \\
\hline Suffering & $\begin{array}{l}\text { Impact on nurse as result of } \\
\text { moral distress (Corley, 2002) }\end{array}$ & $\begin{array}{l}\text { Leads to resignation, burn-out, and exiting } \\
\text { the profession (Corley, 2002) }\end{array}$ \\
\hline
\end{tabular}

Note. From "Nurse Moral Distress: A Proposed Theory and Research Agenda," by M. C. Corley, 2002, Nursing Ethics, 9(6), 636-650. 


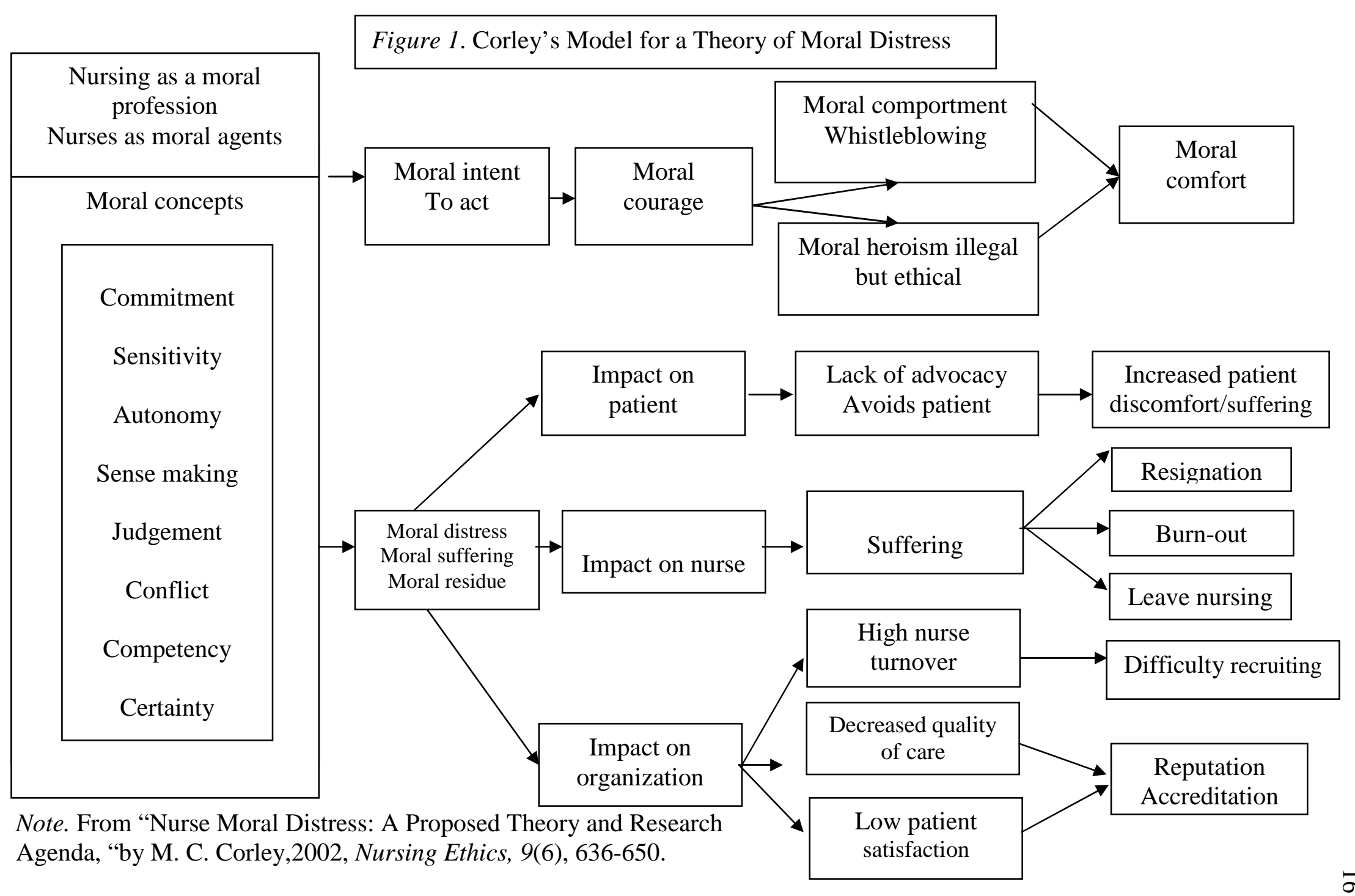


Moral distress impacts patients, nurses, and organizations. If the nurse is unable to advocate for the patient and avoidance behaviors occur, increased patient suffering can result. If moral distress results in high nurse turnover, the organization may have difficulty recruiting nurses to replace those who have left. If moral distress leads to decreased quality of care and low patient satisfaction, the reputation and accreditation of the organization is jeopardized. The suffering that nurses incur from moral distress is great. Rushton posits that moral distress is a particular type of suffering and that unrelieved moral distress jeopardizes nurses' sense of self-worth and threatens their integrity (2006).

Corley (2002) recognizes the impact moral distress has on the nurse in terms of suffering and that it leads to resignation, burn-out, and exodus from the profession. It is the impact of moral distress on the nurse rather than factors contributing to its development that is the focus of this study. As institutional constraints are thought to influence the development of moral distress, the organizational perspective must also be considered. Within the context of health care organizations, it has been proposed that decreased levels of moral distress are present when nurses are influential in their work settings and are more likely to be involved in active resolution of a dilemma (Penticuff \& Walden, 2000); have high levels of ethics work satisfaction (McDaniel, 1995); have good relationships with peers, patients, managers, physicians, and administration (Olson, 1998); and work in institutions that have policies that guide practice (Hutchinson, 1990). These propositions from the organizational perspective reflect the external context-the work environment—of Corley's theoretical model. 


\section{Quantitative Methods}

Examining moral distress with a sample of 111 nurse-members of the American Association of Critical-Care Nurses (AACN), Corley (1995) used the 32-item MDS to identify similarities and differences between critical care and non-critical care nurses. Three domains of moral distress were identified through factor analysis. The domains were aggressive care, honesty, and action response. Nurses working in non-intensive care settings reported higher levels of moral distress on the aggressive care domain compared to nurses in intensive care $(\mathrm{F}=5.8, P=.02)$. Overall, mean scores reflected lower levels of moral distress ranging from 2 and 3 on a 7-point scale, but some nurses experienced high levels of moral distress on selected items. Twelve percent of these nurses reported having previously resigned a position due to moral distress.

Corley et al. (2005) studied a convenience sample of 106 registered nurses working on medical and surgical units in a mid-Atlantic city. The purpose of the descriptive, correlational study using the 38-item MDS and the Ethical Environment Questionnaire (EEQ) was to examine whether the intensity of moral distress was related to frequency of moral distress, and, if the nature of the ethical environment affected nurse moral distress intensity and frequency. The EEQ is a 20-item questionnaire that measures the degree to which a health care setting exhibits an ethical environment. Moral distress Intensity was significantly correlated with moral distress frequency $(r=0.42, P=0.01)$. Moral distress Intensity was correlated with African American race (Kendall's tau=0.27, $\mathrm{p}=0.01)$ and negatively correlated with age $(r=-0.215, P=0.05)$. Moral distress Frequency was negatively correlated with the EEQ $(r=-0.42, P=0.01)$. The EEQ predicted moral 
distress intensity $(F=1.65, P=0.038)$ reflecting the significant impact that environment had on the experience of moral distress for practicing nurses in these medical and surgical units. Additionally, more than $25 \%$ of the nurses reported having previously left a position due to moral distress. This resignation rate further supports the need to identify strategies/interventions to assist nurses in coping with moral distress.

The relationships among moral distress, ethical climate, physician/nurse collaboration, and satisfaction with quality of care were the focus of a study by Hamric \& Blackhall (2007) exploring the perspectives of 196 nurses' and 29 physicians' on caring for dying patients in critical care units in two different hospitals. A 19-item version of the MDS was used along with McDaniel's Ethics Environment Questionnaire, Olson's Hospital Ethical Climate Survey, and Hojat's Attitude Scale. At the first site, investigators found that nurses had lower collaboration $(p<.001)$, higher moral distress $(p<.001)$, more negative ethical environments $(p<.001)$, and less satisfaction with quality of care $(p<.005)$, than did physicians. Pressure to continue what they believed was unwarranted aggressive treatment created the highest moral distress for both nurses and physicians. Nurses reported more frequent situations involving moral distress than physicians. At Site 1, $1 \%$ of nurses reported leaving a position and $23 \%$ had considered leaving due to discomfort about the way end-of-life care was provided in their institution. At the second site, $17 \%$ had left and $28 \%$ had considered leaving. However, this data must consider the fact that at Site 1 the question asked specifically about end-of-life care, while at Site 2 the question was reworded to ask about patient care. Nurses with higher moral distress scores had lower satisfaction with quality of care $(p<.001)$, lower 
perception of ethical environment $(p<.001)$, and lower perception of collaboration $(p<.001)$. The most highly ranked morally distressing situation for nurses at both sites was following the family's wishes to continue life support even though they believed it was not in the patient's best interest. Other morally distressing situations occurred when initiating lifesaving actions that prolonged death and continuing to participate in patient care when no one would make the decision to "pull the plug".

In a 2004 study, Meltzer and Huckabay surveyed 60 critical care nurses (51 females, 9 males) to examine the relationship between the frequency of moral distress and emotional exhaustion. Using a modified version of the MDS and Maslach's Burnout Inventory, it was found that the frequency of moral distress in instances of futile care was significantly correlated with emotional exhaustion $(r=0.317, P=.05)$. Significance was also shown in a linear regression analysis with MDS frequency scores $\left(R^{2}=0.10\right)$ associated with MBI emotional exhaustion scores $(\mathrm{F}=6.47, d f=1,58, P=.01)$. Nurses with a bachelor's degree in nursing or higher had significantly higher scores $(\mathrm{F}=4.27, P=.009)$ on the MDS painful feelings subscale than did nurses with an associate degree in nursing. Nurses who considered religion to have no importance in their lives had significantly higher scores $(\mathrm{F}=3.43, P=.05)$ on the MBI emotional exhaustion subscale than did those who reported that religion was very important in their lives.

Janvier et al. (2007) equated moral distress to ethical confrontation and examined its occurrence in 115 nurses and 164 residents in a neonatal intensive care unit (NICU) using anonymous questionnaires. The authors reported that $35 \%$ of nurses and $19 \%$ of residents experienced frequent moral distress/ethical confrontation which was not 
associated with religion, level of training, years of practice, sex, age, or having children or not for either of the groups. Nurses work setting was categorized by location - those who worked in the outborn NICU, inborn NICU, and delivery room. There was a higher frequency of ethical confrontation in nurses working in the outborn NICU (56\%) compared to the inborn NICU $(22 \%)$ and delivery $(24 \%)(P<0.05)$. The investigators acknowledged the impact of moral distress on the morale of health care providers, burnout, turnover, staff satisfaction, and the provision of quality care.

The MDS was used to explore the prevalence and contributing factors of moral distress with 260 medical and surgical nurses. Intensity of moral distress was found to be high in situations of futile care, deception, euthanasia, and for certain institutional factors. Predictors for high intensity of moral distress scores were age $>34$ years associated with futile care $(P=0.04)$, current employment $<3$ years associated with futile care and deception $(P=0.04)$, and nursing experience $>6$ years associated with nursing practice $(P=0.04)$, futile care $(P=0.001)$, and deception $(P=0.03)$. Predictors for high scores for frequency were age $>34$ years associated with futile care $(P=0.006)$, current employment $>3$ years associated with futile care $(P=0.007)$ and deception $(P=0.04)$, and nursing experience $>6$ years associated with nursing practice $(P=0.0007)$, institutional factors $(P=0.004)$, futile care $(P=<0.0001)$, and euthanasia $(P=<0.0001)$. The highest scores for Intensity in all categories were of nurses caring for oncology and transplant patients (Rice et al., 2008). 


\section{Qualitative Methods}

In interviews with 12 critical care nurses, Gutierrez (2005) examined moral conflicts, moral judgment, and constraints to moral action that lead to moral distress. Moral conflicts most frequently reported included; overly aggressive medical treatment (92\%), inappropriate use of health care resources (75\%), physician giving incomplete/inaccurate information to patient and/or family (67\%), and lack of respect for patient wishes by physicians (67\%). Situations of moral judgment included; provision of supportive care only (67\%), no resuscitation during cardiac/respiratory arrest (67\%), complete/accurate information given to patient/family by physician (50\%), and patient wishes upheld/respected by physician (50\%). The most common constraint that prevented nurses from acting on their moral judgment or resolving a moral conflict was conflicting goals between the patient, physician, family, and nurse. Effects of moral distress on nurses included; sadness (67\%), anger (67\%), reluctance to come to work/care for patients (50\%), frustration (42\%), emotional/physical withdrawal from others (42\%), increased desire to advocate for patient (25\%), and guilt (17\%). Effects of moral distress on provision of care included; requests to not care for a patient (58\%), decreased interaction with family (33\%), decreased frequency of physical care (17\%), and less personalized care $(17 \%)$.

In investigating moral distress, advocacy, and burnout in 10 critical care nurses, Sundin-Huard and Fahy (1999) conducted an interpretive interactionist study and found that unsuccessful attempts at advocacy intensified moral distress, frustration and anger, and resulted in relocation within the hospital, scapegoating, and burnout. In response to 
these situations, nurses 1) anticipated possible negative effects and the risk of retribution and did nothing, 2) used covert communication strategies to alleviate suffering of patients and their own moral distress, or 3) advocated directly by confronting the doctor, which in this study was not successful and resulted in further moral distress, frustration, and anger. Nurses in this study indicated their desire to be involved in ethical decision-making and that this involvement may lessen moral distress and their sense of powerlessness.

Ferrell (2006) examined 108 nurses' narrative descriptions of their experiences of moral distress when witnessing medically futile care. Participants were asked how the experience affected them and the profession of nursing. The most common conflict the nurses identified as causing moral distress was aggressive care/aggressive care denying palliative care. Other conflicts included use of ventilator or life support, code status and resuscitation, nutrition and hydration, and blood transfusions. Examples included patients being denied pain management, futile use of chemotherapy or dialysis, and use of surgery or diagnostic procedures when they were deemed to be futile. Geriatric patients were the most common group followed by those with cancer. The most common response related to how the experience of moral distress affected the nurses was that it made them become strong patient advocates. Other responses included feelings of demoralization, powerlessness, helplessness, hopelessness, frustration, anger, distress, or guilt for having failed the patients. Some nurses reported that the experience caused them to change their practice area to hospice or palliative care.

In a case study using a narrative approach and content analysis, Severinsson (2003) examined data collected from a 120-minute interview with a single community 
nurse. The nurse described her work as very busy with long hours, difficult situations, shortcomings, lack of support and difficulties with management. Moral distress and burnout centered around three themes: shortcomings and health problems, being between suffering and desire, and responsibility for oneself. Suffering occurred when the nurse found herself facing moral dilemmas while having no control over the outcome, resulting in emotional distress. Witnessing patient suffering and not being able to relieve that suffering left the nurse vulnerable to moral distress. She experienced a sense of blame for the suffering, as well as grief, guilt, and fear. A desire for confirmation and support from the supervisor and colleagues was expressed. Themes were all related to the nurse's identity, personal experiences, reflections on ethical problems and existential issues of suffering, and responsibilities and difficulties nurses face. Moral distress was generally met with silence and generated feelings of shame.

O'Haire and Blackford (2005) used in-depth and focus group interviews with nine pediatric nurses, in conducting a study informed by grounded theory to determine conditions that may lead to moral distress. Nurses' inability to act as moral agents when events occurred that they believed were not in the best interests of the child resulted in moral distress. Disagreement between nurses and parents about the provision of care for their child was a significant source of moral distress. Feelings of anger, frustration, and powerlessness were identified. Nurses avoided conflicts that were stressful and hard in order to deal with the moral distress, and often reacted by providing only the minimum of care to the patient. 


\section{Mixed Methods}

In a descriptive, exploratory study examining moral distress of 28 nurses in a medical intensive care unit, using the MDS and an open-ended questionnaire, Elpern et al. (2005) found moderate levels of moral distress Intensity overall (3.66, range 1.765.79, SD 1.73). The situations involving moral distress did not occur very frequently (1.73, range 0.74-4.42, SD 0.90), however. On a 7-point Likert scale, the highest levels of moral distress intensity (5.57) and moral distress frequency (4.63) correlated with provision of aggressive care to patients not expected to benefit from that care. The only significant demographic variable, which was positively correlated with moral distress scores $(r=.0476, P=0.02)$, was years of experience in nursing. Moral distress adversely affected job satisfaction, retention, psychological and physical well-being, self-image, and spirituality. Experience of moral distress influenced attitudes toward advance directives and participation in blood and organ donation. In addition, respondents reported psychological and physical responses such as anxiety, fear, depression, a sense of powerlessness, hopelessness, lack of support, and insomnia.

In a modified phenomenological study, Hanna (2005) used both quantitative and qualitative methods to investigate the moral distress of 10 nurses who had assisted with elective abortions. The Moral Distress Screening Form was used to gather quantitative data and the Abortion Experience Survey for qualitative data. Copies of both of these instruments were included in the published work, but little of the quantitative data was provided. Moral distress intensity was rated none/low by 2 participants, moderate by 4 and high by 6 . Frequency ranged from never (1/12), 1-10 occasions (8/12), > 50 
occasions (1/12), and >100 occasions (2/12). Nine of the twelve nurses participated willingly in the abortion procedures. Study participants were initially asked two questions: "What is the lived experience of moral distress related to nurses' participation in legal, elective, surgically induced abortions?" and "Can you describe, in as much detail as possible, your experience when you were assigned to participate in elective abortions". Five properties of moral distress were identified in this study: perception, pain, valuing, altered participation, and perspective, and three types of moral distress: shocked, muted, and suppressed (persistent). The most prominent of the properties was perception in the form of visceral discernment, which the author defined as a precognitive, bodilyexperienced and conscious perception, which is cognitively known and recognizes an objective good (the moral end). Shocked (declared) moral distress is abrupt and intensely experienced with the initial perception of harm. Muted moral distress is an interior experience, but reflects an exterior silence and includes headache, nausea, and fatigue. Suppressed (persistent) moral distress blocked reflective self-reflection related to the experience and resulted in fatigue, depression, migraine headaches, and gastrointestinal upset. An additional element that was identified in the study was evolving moral distress, which developed over time as the person spoke out with greater force and to larger groups to attempt to right the wrong they believed existed (Hanna, 2005).

In a study by Zuzelo (2007), the MDS and an open-ended questionnaire were used to gather data on moral distress and morally distressing events from a convenience sample of 100 registered nurses employed as direct care providers drawn from a variety of inpatient units. The largest group of nurses $(n=44)$ worked in neonatal and adult 
critical care units. Nurses identified moral distress as having a negative affect on their practice as well as on patient outcomes. Using the MDS's 7-point scale for Intensity $(0=$ none, $6=$ great extent $)$ and Frequency $(0=$ never, $6=$ very frequently), unsafe staffing levels were identified as the most morally stressing event $(\mathrm{M}=4.14, \mathrm{SD}=1.93)$ but did not occur frequently ( $\mathrm{M}=2.84)$. Nurses felt moral distress when required to work with physicians they believed to be incompetent $(M=3.95)$, but this occurred infrequently $(\mathrm{M}=2.36, \mathrm{SD}=1.75)$. Working with nurses $(\mathrm{M}=3.74, \mathrm{SD}=1.9)$, nursing assistants $(\mathrm{M}=3.41, \mathrm{SD}=2.15)$, and non-licensed personnel $(\mathrm{M}=3.26, \mathrm{SD}=2.21)$ that participants believed were incompetent was also morally distressing. Following ineffective pain medication regimens $(\mathrm{M}=3.7, \mathrm{SD}=1.89)$ and carrying out orders for unnecessary tests and treatments $(\mathrm{M}=3.65, \mathrm{SD}=1.74)$ also resulted in moral distress.

While most studies on moral distress have been done in acute care settings, some research has been conducted in long-term care environments. Green and Jeffers (2006) conducted interviews with six nurses in a long-term care setting to determine if moral distress was present in nurses working in this environment, describe moral distress's impact on residents and themselves, and identify what helped them deal with moral distress. All of the nurses reported experiencing moral distress with the sources stemming from allocation of resources, quality of life issues, and end-of-life care. Responses to moral distress included feelings of frustration, anger, and depression. Resigning their positions or leaving the nursing profession were identified as possible courses of action. Communication via talking to supervisors, other nurses, and interdisciplinary coworkers helped alleviate the moral distress. Many of the nurses reported moral distress as a 
personal and professional growth experience. One nurse said, "You figure out how to grow from it and use it [to get through] the next situation." Another said, "Moral distress opens your eyes and formulates [moral] thinking ...[and] where your mind and your feelings are" (p. 8).

Seventy-one advanced practice nurses were surveyed in a descriptive study by Laabs (2005) to identify ethical issues encountered, types of moral problems related to those issues, and the level of distress experienced. Respondents identified frustration and lack of power to effect change as morally distressing. The issue with the greatest frequency was patient refusal of appropriate treatment (62\% occasionally, $10 \%$ commonly). The majority (67\%) rarely (28\%) or never (39\%) experienced ethical issues listed in the survey. Contributing to moral distress were employer constraints, including allotted time spent with patients and performance based on volume of patients seen rather than quality of care. As with nurses in critical care settings, some of these nurses left their positions. Some considered leaving advanced practice altogether.

\section{Interdisciplinary Studies}

A few studies have investigated the experience of moral distress in health care providers other than nurses. In an ethnographic study, Carpenter (2005) interviewed 10 physical therapists working in rehabilitation and found that moral distress occurred when the physical therapists were unable to help patients due to decisions made by others and the misuse of rehabilitation resources. Multiple interviews with participants resulted in data saturation. Inaccessibility of services and lack of trust between clients and health care professionals resulted in feelings of frustration, anger, powerlessness, and sadness. A 
lack of fairness and discrimination against specific groups was distressing, as well as withholding information from clients. The process of moral reasoning was reflected in the physical therapists attempts to collaborate with other health care team members to circumvent decisions and policies that they perceived as being harmful to their clients.

Norwegian doctors were surveyed in a study by Førde, and Aasland (2008) to examine tolerance of criticism, moral distress, and values of their work organization. Participants were presented with nine statements identified by the investigators as dealing with moral distress and asked to rate to what extent they found the items distressing. Five options were provided ranging from 'not distressing at all' to 'very distressing' with inclusion of a 'don't know' option. Examples of statements and percentage of participants that found the item very distressing included 'Treatment not likely to be effective, is given' (14.1\%), 'elderly patients are not prioritized' (8.1\%), 'care for patients is limited due to time constraints' (25.5\%), and 'I must sometimes act against my conscience' $(26.7 \%)$. Time spent on documentation and administrative activities was a source of distress for over half (55\%) of participants. Male doctors were less stressed than females. A lack of prioritization for elderly patients was distressing for older doctors, while younger doctors were more stressed by time constraints.

In a phenomenological study, Austin et al. (2005b) examined the moral distress of psychologists working in mental health care to identify situations that they found morally distressing and environmental supports that influence ethical practice. Participants described feeling "angry, frustrated, depressed, ashamed, embarrassed, heartsick, grief, miserable, in pain, sad, and ineffective. Their descriptive comments 
included 'I can't stand it. I just can't stand it; It's intolerable. I can't tolerate it; and I still feel horrible" (p. 200). The word frustrated was used frequently in the participant's descriptions of moral distress. An element of avoidance is reported along with references to acting in secret. One participant covertly acted to contact an outside group to advocate for a patient as he felt he could not. Acting in secret helped alleviate his moral distress.

Other themes reported were to speak or stay silent, to stay or to go, and the need to be able to look in the mirror. Knowing one is making a difference and being supported by colleagues were helpful in coping with moral distress. As with other investigations of moral distress, Austin et al. reiterate that moral distress has lasting effects and that professionals may eventually feel 'burnt out', resign their positions, or leave their profession entirely. The suggestion is made that rather than focus on eliminating moral distress, that efforts be taken to "create practice environments where great moral courage is reserved for the difficult ethical explorations demanded of us, rather than being a requirement for the daily struggle of doing our work while despairing and feeling alone" (p. 211).

\section{Other Models of Moral Distress}

In addition to Corley's model, two other models of moral distress have been developed and are summarized here.

\section{Wilkinson's Moral Distress Model}

Wilkinson defines moral distress as "the psychological disequilibrium and negative feeling state experienced when a person makes a moral decision but does not follow through by performing the moral behavior indicated by that decision" $(1987 / 88$, p. 
16). The phenomenon involves both experience and effect. The experience component includes a situation involving a moral issue, a decision about what action the nurse should take, and contextual constraints to that action leading to psychological disequilibrium and painful feelings. The degree to which the nurse feels responsible for the patient's well-being will influence the strength of the feelings. The effect component involves coping behaviors whereby the nurse attempts resolution of the painful feelings and may include avoidance of the patient. Frequent exposure to morally-charged situations impairs the nurse's ability to cope effectively. Unsuccessful coping threatens the integrity of the nurse who may respond with an inability to provide patient care leading to attrition and resignation (Wilkinson, 1987/88). The development of this model came from Wilkinson's qualitative study with 24 hospital nurses and the data analysis conducted after face-to-face interviews with participants. While other researchers have referenced Wilkinson's work, no studies were found in a database search specifically using this model.

\section{Model of Military Nursing Moral Distress}

Concerned about the extreme environmental conditions that impact nurses in the military, Fry, Harvey, Hurley, and Foley (2002) developed a model of moral distress in military nursing. They acknowledged Wilkinson's (1987/1988) model, and the stages (initial and reactive) of moral distress as defined by Jameton (1993), but consider as well the crisis situations of military deployments. Moral distress in military nursing is a process that involves conflicting values and begins with the nurse's arousal to the need for a moral judgment and moral action. The process continues with the nurse appraising 
the situation, making a judgment, and taking action if there are no barriers to that action. If barriers are present, initial moral distress occurs. If barriers to action cannot be resolved, reactive moral distress occurs. While the domains are similar to those identified by Jameton (1993) and Wilkinson, the contextual and predisposing factors for the development of moral distress are different for nurses in military service. A database search revealed no other studies using Fry et al's model. However, Almonte (2009) suggests that there is a need for predeployment training on moral distress and this model could be used in future research to inform the nature of moral distress in Navy nurses.

\section{Avoidance Thoughts and Behaviors}

Avoidance is defined as conscious efforts a person takes to avoid thinking about an event and to actively avoid reminders of the event (Hogan \& Schmidt, 2002). It can be expressed through physical as well as psychosocial manifestations. It is the absence of verbal, physical, and social contact with patients, including lack of eye contact, decreased physical proximity, decreased time spent with the patient, and negative verbal mannerisms (Siminoff, Erlen, \& Sereika, 1998). Nurses' avoidance behavior has been reported in various studies (Gutierrez, 2005; Healy \& McKay, 2000; Kagan, Ovadia, \&

Kaneti, 2009; Lambert, Lambert, Petrini, Li, \& Zhang, 2007; Mackintosh, 2007;

Röndahl, Innala, \& Carlsson, 2003; Tyson \& Pongruengphant, 1996; Wong, Leung, \& So,2001) and has been associated with repeated exposure to morally distressing situations (Gutierrez, 2005).

In a phenomenological study conducted by Hanna (2005) with 10 nurses who participated in elective abortions, avoidance behaviors were used as a coping mechanism 
in response to moral distress. Nurses avoided patients as well as discussions with others while they were actively experiencing moral distress. Nurses who unwillingly participated experienced anticipatory dread. When they were unsuccessful in avoiding prior participation, they feared future mandated assignments. Nurses who initially participated willingly but later perceived a sense of harm rejected future involvement or worked reluctantly with resignation. One nurse reported using alcohol, drugs, and other escape behaviors.

Siminoff et al. (1998) observed avoidance behaviors in nurses caring for patients with acquired immunodeficiency syndrome (AIDS) and general medical conditions. Ninety-eight triads (nurse, patient with AIDS, patient with medical condition) participated in the study. The effect size for correlations for this sample was reported as 0.25 at a significance level of 0.05 with at least $80 \%$ power. A 'checklist' tool was developed from content analysis of the descriptions of nurses' caregiving activities and verbal and nonverbal interactions with patients. Quality of care was measured using Qualpacs, a 68-item observational tool using a five-point scale of 1 (poorest care) to 5 (best care). Type-specific avoidance behaviors, including spending less time with patients and fewer positive verbal mannerisms were associated with decreased quality of care. There was a significant difference between level of patient education and time spent with patients $(t=-2.252, p=0.027)$, in that avoidance behaviors were associated with less patient education. Percentage of positive verbal mannerisms was the only variable significantly associated with quality of care; patients with AIDS $(0.0028, p=<0.05)$, general medical patients (0.0014), and average of both groups (0.0026). The total 
proportion of variance for the model was small $\left(R^{2}=0.0145\right)$ with the total model explaining a small fraction $\left(R^{2}=0.1035\right)$ of the variance in quality of care.

Lambert, Lambert, and Ito (2004) reported escape/avoidance coping, likelihood to leave a current position, and lack of workplace support as the best predictors of poor mental health in a sample of 310 Japanese hospital nurses. These predictors were not only not helpful in maintaining mental well-being, but were detrimental to nurses' mental health. The Ways of Coping Questionnaire (WOCQ) was used to assess eight ways of coping, including distancing and escape-avoidance. Items are measured using a fourpoint scale with responses ranging from 0 (does not apply or not used) to 3 (used a great deal). High scores indicate frequent use of the specific items to cope with stressful events. Distancing was significantly positively correlated with age $(r=0.14, p=0.05)$, years worked as a nurse $(r=0.15, p=0.05)$, escape-avoidance $(r=0.49, p=0.01)$, conflict with physicians $(r=0.15, p=0.01)$, and death and dying $(r=0.18, p=0.01)$. Escape-avoidance was significantly positively correlated with likelihood to leave current position $(r=0.24, p=0.01)$, workload $(r=0.22, p=0.01)$, and death and dying $(r=$ $0.26, p=0.01)$

Healy and McKay (2000) also used the WOCQ to study the relationships between nurses' work-related stress and coping strategies with a sample of 129 Australian nurses. Scores from the WOCQ and the Profile of Mood States (POMS) checklist were examined. The POMS uses 37 adjectives to assess one positive and five negative mood states with respondents rating their feelings from 0 (not at all) to 4 (extremely). Escapeavoidance coping was a significant predictor $(\beta=0.28, P=0.05)$ of POMS scores. 
Avoidance was reported as the least used method of coping, but resulted in higher levels of mental distress when it was used. Overall, $86(67 \%)$ of nurses in the study reported thinking about finding a position outside of nursing.

Peter and Liaschenko (2004) debate the perils of nurses' proximity, or physical nearness, that is intrinsic in the nurse-patient relationship. The proximity to patients affects nurses' moral responsiveness, specifically nurses' moral distress. The nursepatient relationship requires close proximity between care-giver and recipient of care. Proximity fosters nurse action, but in some situations (i.e., moral distress) may cause nurses to ignore and turn away and abandon or avoid patients. This may allow the nurse to maintain psychosocial integrity, but it deprives the patient of the benefits of a genuine care-giver care-receiver relationship. It is the closeness that instills moral responsibility. Those who lack physical proximity to the patient may not perceive moral responsibility or moral agency as inherent in their role. As Peter and Liaschenko suggest, decisions that result in the suffering of others are less distressing when they are not observed. As direct care givers, nurses live the experience of those decisions and are most vulnerable to their outcomes. The ensuing moral distress may be proportionately related to the intensity and frequency of exposure.

\section{Limitations of Previous Studies}

\section{Sample Size}

Sample size may have limited the validity of findings reported in the literature review. In the studies using quantitative methods, sample sizes ranged from 12 to 260 , suggesting some studies may have been underpowered. Other studies of moral distress 
using mixed methods may also have been underpowered. In a study by Elpern (2005), with 28 nurses who worked in a medical intensive care unit, the only significant association was a positive correlation between years of experience in nursing and moral distress scores $(r=.0476 ; P=.02)$. While Hamric and Blackhall (2007) did not report a power analysis for their study, they concede that lack of statistical significance of some correlations may be due to the lack of power that occurs with a small sample size; for example, there was a negative relationship between satisfaction and moral distress $(r=$ $-.36)$, but this was not statistically significant.

Due to small sample size in Laabs' (2005) study, the required assumptions underlying chi-square calculations for nonparametric analysis of association could not be met. Schwenzer and Wang (2006) report the absence of some of the scale items with exploratory factor analysis which may have been due to small sample size. The ratio of sample size to variables in this study was $2: 1$ with 57 participants, which is below the suggested minimum sample size. The investigators allow that a larger sample size would have enhanced power, but sample size estimation a priori was not done because it was a pilot study. Power analysis was not reported in the studies of Corley $(1995,2005)$, Meltzer and Huckabay (2004), Janvier et al. (2007), or Rice (2008).

Sample size in qualitative studies is based on reaching data saturation. With indepth information, even a small sample size may achieve redundancy. Polit and Hungler (1999) suggest that 10 cases may be sufficient with a fairly homogeneous sample. Phenomenological studies such as those conducted by Gutierrez $(2005, \mathrm{~N}=12)$ and Hanna (2005, N = 12), both consisting of homogeneous groups, generally have sample 
sizes of 10 or less. Nieswiadomy (1998) reviewed qualitative studies published in the literature during 1996 and found sample sizes ranging from 6 to 12 for phenomenological studies, and varied from 12 to 33 for ethnographic and grounded theory-based studies.

Some inconsistencies exist among experts in determination of sample size. While Polit and Hungler's (1999) recommendation of 10 or fewer participants is similar to Nieswiadomy's (1998) range of 6 to 12 for phenomenological studies, both recommend a sample size of 20 to 40 participants for ethnographic or grounded theory investigations. More recently, Polit and Beck (2006) suggest 20 to 30 participants for grounded theory and 25 to 50 informants for ethnographic research. Storch, Rodney, Pauly, Brown, and Starzomski (2002) exceeded all of these numbers with a sample of 87 in a qualitative study using descriptive inquiry. O'Haire, and Blackford's (2005) grounded theory study enrolled only nine subjects, suggesting data saturation may not have been reached. Sundin-Huard and Fahy (1999) conducted an interpretive interactionist study engaging 10 participants. A later study by Sundin and Fahy (2008) delineates interpretive interactionism as grounded theory and as such a sample of 10 is insufficient. With the exception of Severinsson's (2003) case study, qualitative studies reported here had sample sizes of 9 to 108 .

Ferrell's (2006) investigation had an unusually large convenience sample for a qualitative study. One hundred eight nurses attending continuing education courses on end-of-life care were recruited. These nurses served as key informants allowing the researcher access to a myriad of narratives that would not have been possible with a smaller group. 


\section{Lack of Clarity in Directions for Completing Instruments}

A number of studies had significant limitations. Some respondents in Zuzelo's (2007) study reported that the directions to complete the research instrument (MDS) were difficult to comprehend, which may explain why some did not complete both the occurrence and frequency scales $(n=13)$ and some $(\mathrm{n}=5)$ left $>33 \%$ of items blank. These responses were excluded.

\section{Single Exemplar}

The interpretive interactionism framework used by Sundin-Huard and Fahy (1999) utilized a single incident exemplar to examine moral distress, advocacy, and burnout. While facilitating understanding of a very specific incident, the knowledge gained in this type of approach limits understanding of the concepts in other scenarios, situations, and environments.

\section{Other Limitations}

Objectivity and voluntariness in the Gutierrez (2005) study may have been threatened due to the researcher having a professional relationship with the participants. Inconsistencies in sampling were apparent in the Hamric and Blackhall (2007) study where participants at one of the sites were not paid for involvement, and administration held a lesser degree of interest in the study.

\section{Summary of the Literature}

\section{Conceptualization of Moral Distress}

Three models of moral distress have been proposed in the literature. The earliest model was developed as part of a study to generate theory about the moral aspects of 
nursing and quality of patient care (Wilkinson, 1987/88). This model acknowledged that moral distress had two components; the experience, involving a situation of moral concern, a decision about what action ought to be taken, and contextual constraints to that action; and the effect, involving coping behaviors the nurse uses to mitigate the painful feelings that arise from the initial experience. A second model was developed by Fry et al. (2002) that used Wilkinson's work, but adapted it to the contextual and predisposing factors specific to nurses in the military. A third model, Corley's, has drawn from the work of Jameton (1993) and Wilkinson and proposes what occurs when a nurse is unable or perceives she is unable to advocate for a patient. The model is set in the context of the work environment and the nurses' psychological responses. Moral concepts relevant to the theory are considered from the individual and organizational perspectives. Moral competence is of prime importance in the experience of moral distress and its development is dependent on the incorporation of the moral concepts into the nurse's value system (Corley, 2002). It is this model that will be the conceptual framework for the current study.

Concepts that have been studied in relationship to moral distress include ethical climate, burnout/emotional exhaustion, quality of patient care, and intent to turnover, as well as individual nurse characteristics. The majority of studies used the Moral Distress Scale as a measurement tool. Other tools that have been used include the Ethical Environment Questionnaire (Corley et al., 2005), Olson's Hospital Ethical Climate Survey (Hamric \& Blackhall, 2007; Pauly, Varcoe, Storch, \& Newton, 2009), and Maslach’s Burnout Inventory (Meltzer \& Huckabay, 2004). 


\section{Empirical Evidence of Moral Distress}

The majority of studies on moral distress have been done with nurses working in critical care units where ethical dilemmas often arise due to the nature of patient conditions in these settings. Situations most often related to moral distress involved endof-life issues including pressure from physicians and/or families to continue aggressive treatment deemed inappropriate, suffering due to inadequate pain medication, working with other health care providers who were perceived as incompetent, and working with unsafe staffing levels. Effects of moral distress on nurses included anger, frustration, sadness, avoidance of patients, emotional/physical withdrawal from others, powerlessness, attrition, and resignation.

Few studies have been done in long-term care settings, but the nurses in these environments do report moral distress with responses including feelings of frustration, anger, and depression. Allocation of resources and quality of life/end-of-life issues were sources of moral distress. Resignation and/or exiting the profession altogether were considered as well in these settings. Advanced practice nurses were not immune to moral distress and identified frustration, lack of power to effect change, employer constraints, and volume of patients seen valued over quality of care as common sources.

Studies have been done with non-nurse populations but the effects on these health care providers were similar with reports of feelings of frustration, anger, depression, powerlessness, and sadness. Sources ranged from the provision of futile care and unsafe staffing to participating in deception. 
Avoidance behaviors of nurses have been examined in relationship to various practice settings and patient care situations. Few studies have been conducted that specifically examine these behaviors in relationship to moral distress. Higher levels and/or frequent exposure to moral distress may increase avoidance behaviors. When nurses avoid patients, poor outcomes with increased morbidity and mortality of patients occurs. Avoidance behavior and moral distress have been associated with nurse attrition and retention. These findings lend support to the aim of determining if there is a significant relationship between moral distress and avoidance behaviors by nurses and if this relationship remains after adjusting for age, gender, and race/ethnicity.

In conclusion, moral distress of nurses has been shown to occur most often in critical care settings where ethical dilemmas often arise due to the nature of patient conditions. It impacts patients, nurses, and organizations resulting in feelings of frustration, anger, powerlessness, loss of psychosocial integrity, and patient suffering with increased morbidity and mortality. The consequences of moral distress hold significant implications for the future of the nursing workforce as nurses are unable to cope with repeated and intense exposure to this phenomenon and leave the profession altogether. To facilitate a more complete understanding of moral distress, it is imperative that the relationships between moral distress and avoidance behavior be investigated. In addition, this research examined the moral distress of nurses practicing in non-critical care settings which has been less explored in the literature. 


\section{Gaps in Knowledge}

\section{Practice Settings}

Investigations of moral distress in nursing have primarily been done with practitioners in intensive/critical care settings. While the nature of the work in these environments lends itself to moral/ethical issues (while one may resolve an ethical dilemma and not be able to act in accord with one's decision, an ethical dilemma may be but does not have to be the precipitating factor for eventual development of moral distress) that may precipitate moral distress, nurses in other settings may be exposed to similar scenarios, as well as events unique to their practice settings. Studies are needed that seek to identify the presence of moral distress in health care providers in long-term care, clinics, hospice, as well as hospital staff nurses outside of intensive/critical care settings. Advanced practice nurses, nurse educators, and school nurses may have specific patient, colleague, and/or situational events that expose them to moral distress. To identify and quantify the presence of moral distress in these populations, additional tools need to be developed specifically for the environments in which they practice.

\section{Retention of Professional Nurses}

Moral distress has been identified as a factor in nurse retention. In a time when a shortage of nurses threatens to leave healthcare institutions less than adequately staffed, there is a need to more adequately identify precipitating events and strategies to assist those nurses subject to intense and/or frequent episodes of moral distress. In addition to the psychological impact of moral distress on nurses and their resulting exodus from the workforce, the financial loss to healthcare institutions of thousands of dollars invested in 
orientation and training costs of nurses who leave due to unresolved and repeated moral distress is great.

\section{Homogeneity of Sample Populations}

Generalizability of previous findings is limited by sampling of homogeneous populations. Caucasian females have largely been the sample population in past studies. To broaden the scope of knowledge, studies with all males and significant numbers of nurses from various cultural, racial, and ethnic groups need to be included in future studies.

\section{Measurement of Moral Distress}

Development of new instruments that have demonstrated both validity and reliability, and revisions of those currently in use, may foster a more comprehensive understanding of the experience of moral distress. Studies focusing on gender, culture, race and/or ethnic diversity may reveal limitations in current instruments and the need for revisions to incorporate cultural specificity. Hanna (2004) suggests that screening tools need to be developed to study moral distress in the general population, including patients, and acknowledges that methods may differ for young children, adolescents, and adults. Hanna (2005) further posits that "recent attention to the long-term damage that pedophilia can have on boys when they are grown men shows that children probably can experience moral distress" (p. 122).

\section{Avoidance Behaviors}

While avoidance behaviors have been examined in populations of nurses in relationship to stressful in-patient surgical units (Mackintosh, 2007), caring for patients 
with AIDS (Siminoff, Erlen, \& Sereika, 1998), coping with organizational stress (Tyson, Pongruengphant, \& Aggarwal, 2002), and mental distress (Healy \& McKay, 2000), few studies have specifically examined avoidance behaviors related to moral distress. Avoidance behavior in nursing is contrary to the comportment of professional nursing practice. In the Code of Ethics for Nurses, the American Nurses Association (2001) identifies the nurse's primary role as that of advocate in promoting the health, well-being, and safety of the patient. This role entails taking action when the nurse believes incompetent or unethical events have occurred. When nurses engage in avoidance behavior due to moral distress, ensuing events may cause harm to the patient and the integrity of the nurse's practice as well as the profession. It is imperative that future research examine the association of avoidance behavior in nursing and moral distress. 


\section{CHAPTER THREE}

\section{METHODS}

This chapter will describe the methodology utilized in the study. A review of the study purpose and research aims and hypotheses, design, sample, sample characteristics and size, sampling methods, definitions of the variables, measurement instruments and psychometrics, data collection and management, data analysis procedures, and ethical considerations will be included.

\section{Review of the Study Purpose}

Advances in scientific technology and increasing lifespan have presented nurses with new challenges in addressing moral dilemmas and ethical decision-making. Nurses draw from their own moral framework and external standards and guidelines as they attempt to carry out their roles in a manner that is compatible with the mission, policy, and procedures of the institution as well as with other health care providers. Factors beyond their control may hinder nurses' perceived ability to effectively fulfill those roles and act as moral agents for patients and their families. Facing barriers to what they believe to be moral practice, nurses experience the negative feelings, physical symptoms, and psychological disequilibrium known as moral distress. Moral distress has also been associated with poor patient outcomes, including increased morbidity and mortality. Nurses unable to cope with frequent and intense episodes of moral distress may leave the profession as their coping mechanisms are depleted and their felt ability to provide 
quality patient care is impaired. Failed retention contributes to the nursing shortage as well as to significant financial losses to hospitals that have invested large sums of money in clinical orientation programs and internships.

The purpose of this study was to explore the relationships between moral distress and avoidance behavior between nurses currently practicing in critical care and noncritical care settings. This study is innovative in examining the convergence of these two concepts that has been relatively unexplored thus far in the literature. The results of this study provide data on the nature of the relationships of these variables. The empirical indicators of the measurement tools increase understanding of the presence, absence, intensity and frequency of moral distress, and the ways nurses cope with stressful events in their practice. This knowledge will lay the foundation for future research focused on preventing or diminishing the negative consequences of moral distress and facilitating adaptive coping mechanisms of nurses' in critical care as well as non-critical care settings.

\section{Aims and Hypotheses}

Aim 1a. To determine if there is a difference between the intensity and frequency of moral distress of nurses in critical care and non-critical care settings.

Hypothesis 1a: The intensity and frequency of moral distress is greater in critical care nurses compared to non-critical care nurses.

Aim 1b. To determine if there is a difference in mean Moral Distress Scale and Impact of Event Scale scores between critical care and non-critical care nurses and to determine if there is a difference after adjusting for age. 
Hypothesis 1b: There is no difference between moral distress and avoidance

behaviors of nurses in critical care and non-critical care settings.

Aim 2. To determine if there is a correlation between moral distress and avoidance behaviors in critical care and non-critical care nurses.

Hypothesis 2: There is a positive correlation between moral distress and avoidance thoughts and behaviors.

Aim 3. To determine if there is a relationship between moral distress and avoidance behaviors in critical care and non-critical care nurses after adjusting for age.

Hypothesis 3: There is no relationship between moral distress and avoidance

behaviors by nurses after adjusting for age.

\section{Design}

This study uses a descriptive cross-sectional design to compare the relationships of moral distress and avoidance behavior. Table 2 contains a list of variables and measures.

Table 2

Variables and Measures

\begin{tabular}{ll}
\hline Variable & Measure \\
\hline Location of Employment-Critical Care vs. non-Critical Care (IV) & Participant Self-Report \\
Moral Distress (DV) & Moral Distress Scale \\
Avoidance Behavior (DV) & Impact of Event Scale \\
Possible Covariates & \\
Age & Demographic Data Form \\
Gender & Demographic Data Form \\
Race/Ethnicity & Demographic Data Form \\
\hline Note. IV=independent variable. DV=dependent variable. & \\
\end{tabular}




\section{Power Analyses}

In order to achieve $80 \%$ power to detect a difference in mean scores on the MDS between critical care and non-critical care nurses (Aim 1); a sample of 64 per group was needed using a medium effect size according to Cohen's (1969) classification $(d=.50)$ at $\alpha=.05$. For Aim 2, in order to achieve $80 \%$ power to detect a relationship between MDS and IES scores with a medium effect size of $(r=.30)$ at $\alpha=.05$, a sample of 85 per group was needed. For Aim 3, in order to achieve $80 \%$ power to detect a relationship between moral distress and avoidance behaviors in critical care and non-critical care nurses adjusting for age with a medium effect size, a sample of 63 per group was needed. To allow for a low response rate, a sample of 682 was invited to participate.

\section{Sample}

The sample for this study included 96 registered nurses (121 for Aim 1a) who practice, or have practiced, in critical care and/or non-critical care units. Non-critical care units are those without the designation of 'critical care' or 'intensive care' in their respective institutions and this designation was self-reported by participants on the demographic form. This population was chosen as moral distress has been explored mainly with nurses in critical care units where it occurs most often, but there is a need to examine the concept as it occurs in nurses working outside of critical care settings as well. Participants were 18 years of age or older and eligible for the study if they read and understood English. 


\section{Setting}

The settings were a public university web site and nursing classrooms at a private university, both in the Midwest United States.

\section{Measurement Instruments}

\section{Moral Distress Scale (MDS)}

Corley’s original 32-item Moral Distress Scale was developed from 1994 to 1997 to measure the intensity and frequency of moral distress of hospital nurses caring for adult populations. Development of the tool drew from the conceptual work of Jameton (1993) (moral distress in nursing), and the theoretical frameworks of House and Rizzo (1972) (role conflict) and Rokeach and Regan (1980) (values and value systems). House and Rizzo’s (1972) role conflict theory involves allegiance to two organizational authorities. In the context of healthcare and nursing practice, nurses are subject to role conflict when expectations of managers differ from that of physicians. Corley et al. (2001) posit that opposing expectations between those who pay their salaries and those who direct their provision of care are a source of role conflict for nurses. Rokeach's value theory suggests that values are represented in a person's cognitive structure and are conceptions of what are desirable means and ends of action. They are enduring beliefs of personally or socially preferable conduct; standards or criteria for action (Rokeach \& Regan, 1980). Nurses' care is based on their value system which motivates their behavior. Conflict may occur when nurses' values are inconsistent with expectations of physicians and/or the organization in which they practice. 
The MDS includes three domains: individual responsibility, not in patient's best interests, and deception. Role conflict is reflected in Factor 1 of the MDS-individual responsibility. Nursing practice entails more responsibilities than rights, and nurses' responsibilities may be constrained by the absence of authority, further contributing to the experience of moral distress. Role conflict is reflected in Factor 2-not in patient's best interests - in actions such as life-saving treatments that prolong death, and surgery for terminally ill patients. Role conflict is reflected in Factor 3-deception. Deception entails an intentional action to deceive, or a failure to act, and is seen in instances of a partial code or administering medications IV when the patient refuses them orally.

Nurses' values are reflected in the three factors of the MDS. Nurses' perceived ability to act responsibly is threatened when their behavior does not reflect their values in instances such as ignoring nurse medication errors or patient abuse. When nurses are involved in deception or performing procedures without patient consent, a value conflict may occur as the nurse believes that the patient's best interest is not being served. Deception conflicts with nurses' professional role as well as the value system of the profession. Action, or inaction, such as abiding by a physician's request not to discuss code status with a patient, threatens patient autonomy.

The MDS was first used in an investigation with a sample of 111 hospital nurses; 58 members of the American Association of Critical Care Nurses, 36 working in a private hospital, and 22 employed in critical care in a medical center. The scale was modified for use in a 2005 study by Corley et al. on nurses' moral distress and ethical work environments. The sample consisted of 106 registered nurses from medical and surgical 
units in two large medical centers. For this study, six items on pain management, managed care and incompetent health care personnel were added, as well as a revision of the scale to include a zero response option. The earlier scale used a 5-response format ranging from 1 (little/almost never) to 5 (great). The revised scale expanded options to 7 with a range of 0 (none) to 6 (great extent) for the Intensity scale, and 0 (none) to 6 (very frequently) for the Frequency scale. These modifications limit the possibility of comparing the results of this study to prior studies.

Psychometric properties. Content validity was reported by the authors as $100 \%$ after this revised scale was reviewed by three doctorally prepared experts with nursing ethics research experience. Although the experts may have been familiar with ethics, they may not have had nursing experience similar to the nurse participants and, therefore, may not have been the most appropriate evaluators of content validity. Additionally, three experts is generally not sufficient for a review. As the MDS was originally developed for nurses in intensive/critical care settings, the results of this study with medical and surgical nurses may not adequately reflect the true nature of moral distress for these participants.

Overview of modifications/revisions. The MDS has been used in studies with nurses outside of ICU settings, and some studies have used a revised or modified version of the original scale. The original 32-item version was found to be valid and reliable. Corley et al's 2005 study used a revised 38-item version. In discussing instrumentation in their 2005 study using the revised 38-item version of the MDS, Elpern et al., claimed that reliability and validity have been established for the MDS. Meltzer and Huckabay 
(2004) used a modified 34-item version and reported that Cronbach's alphas remained high on the subscales. Except for Corley et al.'s 2005 study, all of these investigations sampled nurses working in ICU settings (see Appendix A). See Table 3 for psychometrics of the MDS.

\section{Impact of Event Scale (IES)}

Avoidance is defined as conscious efforts a person takes to avoid thinking about an event and to actively avoid reminders of the event (Hogan \& Schmidt, 2002) and was measured by using a subscale of the IES (avoidance). The IES consists of 15 items, eight for the avoidance subset. Participants respond to the items based on frequency of occurrence in the past seven days with choices of 'not at all', 'rarely', 'sometimes', or 'often'. Mean scores are computed based on weights assigned for each item.

Psychometric properties. The split half reliability of the total scale was high $(r=$ 0.86). Cronbach's alpha internal consistency was also high (0.82). Reliability of the scale was supported by test-retest results: $r=.87$ for the total scale, $r=.79$ for the Avoidance subscale and $\mathrm{r}=.89$ for Intrusion. Although the Intrusion and Avoidance subscales are associated, they do not measure identical dimensions as shown by a correlation of $r=0.42$ $(p>0.0002)$ between the subscale scores. The subscales had empirical validity, adequate test-retest results, and sensitivity supported by indications of change (Horowitz, Wilner, \& Alvarez, 1979). More recent studies (Davis et al., 2005; Horowitz et al., 2001) show that the IES ratings over a 20-year period are relatively constant, and that the earlier reports of gender differences which had shown higher stress scores in females has been refuted (Sundin \& Horowitz, 2003) (see Appendix B). 
Table 3

Psychometrics of the Moral Distress Scale

\begin{tabular}{|c|c|c|c|c|}
\hline Authors & $\begin{array}{l}\text { Sample } \\
\text { Size }\end{array}$ & Test & Results & $\begin{array}{l}\text { Psychometric } \\
\text { Soundness }\end{array}$ \\
\hline $\begin{array}{l}\text { Meltzer \& } \\
\text { Huckabay, } 2004\end{array}$ & 60 & $\begin{array}{l}\text { Homogeneity } \\
\text { reliability }\end{array}$ & $\begin{array}{l}\text { Intensity, } \alpha=0.95 \\
\text { Frequency, } \alpha=0.96\end{array}$ & High \\
\hline \multirow[t]{4}{*}{$\begin{array}{l}\text { Corley et al., } \\
2001,2005\end{array}$} & $\begin{array}{l}2001 \\
214\end{array}$ & Content validity & $\begin{array}{l}100 \% \text { from } 3 \text { doctorally } \\
\text { prepared experts }\end{array}$ & $\begin{array}{l}\text { Acceptable } \\
\text { support }\end{array}$ \\
\hline & $\begin{array}{l}2005 \\
106\end{array}$ & $\begin{array}{l}\text { Construct validity } \\
\text { - contrasted groups } \\
\text { (critical care and } \\
\text { occupational health } \\
\text { nurses) }\end{array}$ & $\begin{array}{l}\text { OHN did not experience } \\
\text { situations listed on } \\
\text { the MDS }\end{array}$ & $\begin{array}{l}\text { Acceptable } \\
\text { support }\end{array}$ \\
\hline & & $\begin{array}{l}\text { Homogeneity } \\
\text { reliability }\end{array}$ & $\begin{array}{l}\text { Intensity, } \alpha=0.98 \\
\text { Frequency, } \alpha=0.90\end{array}$ & High \\
\hline & & $\begin{array}{l}\text { Stability } \\
\text { reliability } \\
\text { (test-retest, } \\
\text { 3-week interval) }\end{array}$ & $r=0.86(P=<0.01)$ & $\begin{array}{c}\text { Acceptable at } \\
r \geq 0.70\end{array}$ \\
\hline $\begin{array}{l}\text { Hamric \& } \\
\text { Blackhall, } \\
2007\end{array}$ & $\begin{array}{l}196 \mathrm{RNs} \\
29 \mathrm{MDs}\end{array}$ & $\begin{array}{l}\text { Internal } \\
\text { consistency } \\
\text { reliability }\end{array}$ & Cronbach's $\alpha=0.83$ & High \\
\hline Zuzelo, 2007 & 100 & Internal consistency & Cronbach's $\alpha=0.95$ & High \\
\hline
\end{tabular}




\section{Demographic Data Form}

Personal characteristics were assessed using the demographic data form, including gender, age, race, education, and employment history (see Appendix C).

\section{Data Collection Procedures}

Following Human Subjects review and approval, the online survey was created using Qualtrics software. AACN provided a random sample of nurse members and a random subset of 370 nurses were drawn from the membership list. A convenience sample of members of the Rural Nurse Manager's Organization and from the enrollment list of the BSN-Completion students were invited to participate via email. In an effort to increase sample size and power, a convenience sample of students in a master's in nursing program in the Midwest was provided paper and pencil copies of the survey. These records were entered by the principal investigator (PI) into a database for recruitment and tracking purposes. Email communication to potential participants included the topic area of the study and salience of the topic to the participant. Contact information was provided for the PI and the respective Chairs of the Institutional Review Boards at both universities. A link to the survey was provided in the email. Students in the BSN-Completion and master's in nursing programs were assured that their participation, or lack of participation, would not affect their grade in any way. Consent was assumed with submission of the survey. Data cleaning, coding, and entry were completed by the PI. 


\section{Statistical Analyses}

\section{Data Preparation and Screening}

After surveys had been submitted, data were entered into the SPSS ${ }^{\circledR}$ (version 17

(Chicago, IL)) database and visual error-checking procedures were carried out. A random sample of $10 \%$ of the records in the database were selected and compared to the source document for accuracy. When three consecutive randomly selected samples, each consisting of $10 \%$ of the responses, were determined to be without error, the process concluded.

Data were analyzed with SPSS for Windows (version 17 (Chicago, IL)). Significance was set at $\mathrm{p}=0.05$ for all tests. All tests were two-tailed. Demographic data were analyzed with descriptive statistics including frequencies, $t$-tests for continuous data, and chi-square for categorical variables. Inferential tests for each aim are listed below:

Aim 1a: To determine if there was a difference between the intensity and frequency of moral distress of nurses in critical care and non-critical care settings. The $t$ test for independent groups was used to compare differences in mean scores on the MDS between critical care nurses and non-critical care nurses.

Aim 1b: To determine if there was a difference in mean Moral Distress Scale and Impact of Event Scale scores between critical care and non-critical care nurses and to determine if there was a difference after adjusting for age. Multivariate analysis of variance and covariance were used to determine if there was a difference in MDS and 
IES scores between critical care and non-critical care nurses, and to determine if there was a difference after adjusting for age.

Aim 2: To determine if there was a correlation between moral distress and avoidance behaviors in critical care and non-critical care nurses. Pearson product moment correlation $(r)$ was used to determine if there was a significant relationship between moral distress and avoidance behaviors.

Aim 3: To determine if there was a relationship between moral distress and avoidance behaviors in critical care and non-critical care nurses adjusting for age. A multiple linear regression analysis was used to determine if age predicted MDS and/or IES scores.

\section{Human Subjects Protection}

The database with participant information was stored on a password protected computer and accessible only to the PI. Submitted surveys were kept in a locked file in the PI's office. After completion of the study, the data were archived in a locked file in the PI's office and in a password protected database on the PI's PC. The potential risks to participants were minimal and involved psychosocial concerns. A participant may have potentially recalled an event(s) that occurred in their past practice that resulted in moral distress and felt uneasy when completing the survey. This risk was anticipated to be minimal and transitory, and no greater than that experienced during a recall and discussion of the event with a colleague. The potential for risk was explained to participants in the online survey materials. Participants were reminded to avoid providing 
any potential identifying information in the surveys such as name or place of employment.

As the investigator and participants are nurses, there was the possibility that the participants would recognize the investigator's name, have had the investigator as a nursing instructor in the past or present, and/or be a colleague of the investigator. However, surveys were anonymous so the investigator would not know the identities of the participants.

\section{Potential Benefits of the Proposed Research to the Participants and Others}

There may have been some indirect benefits to the participants/nurses if they derived satisfaction from contributing to an important topic to nurses, and participation may have enhanced their ability to cope with moral distress prospectively. The nursing profession, policy makers, and future patients and their families may derive benefit from this study as the results add to the body of knowledge related to nurses' experiences with moral distress. The results also begin to fill the gap in knowledge between nurse moral distress and its association to avoidance behavior.

\section{Inclusion of Women and Minorities}

It was anticipated that the gender and racial/ethnic sample of nurses in this study would resemble the population of nurses across the United States. In the US, women are the dominant group in the RN population. Likewise, there is an underrepresentation of minority nurses in the U.S. As of March 2004, there were an estimated 2,909,357 registered nurses in the United States, of which 2,421,351 were employed in nursing. 
Male nurses comprised $6.1 \%(148,642)$ of the employed population. Racial/ethnic backgrounds included $81.2 \%$ white (non-Hispanic), 4.4\% black/African American (nonHispanic), 3.1\% Asian (non-Hispanic), 0.2\% native Hawaiian/Pacific islander (nonHisp), 0.3\% American Indian/Alaska native (non-Hisp), 1.7\% Hispanic/Latino (any race), $1.5 \%$ two or more races (non-Hispanic), and 7.5\% unknown (U.S. Department of Health and Human Services, n.d.). 


\section{CHAPTER FOUR}

\section{RESULTS}

\section{Data Analysis}

The purpose of this study was to explore the relationship between moral distress and avoidance behavior between nurses currently practicing in critical care and noncritical care settings. Specifically, the study sought to determine; 1) if there was a difference between the intensity and frequency of moral distress of nurses in critical care and non-critical care settings; 2) to determine if there was a difference in mean Moral Distress Scale and Impact of Event Scale scores between critical care and non-critical care nurses, and to determine if there was a difference after adjusting for age; 3 ) to determine if there was a correlation between moral distress and avoidance behaviors and; 4) to determine if there was a relationship between moral distress and avoidance behaviors in critical care and non-critical care nurses after adjusting for age.

This chapter presents the results of the study including data preparation and screening; sampling information; demographic data including age, gender, race, highest level of education, years worked in critical care, geographic location of current employment; the intensity and frequency of moral distress; impact of morally distressing events; avoidance thoughts and behaviors; reliability and validity of the MDS and the IES, and answers to the research questions. Statistical analyses included descriptive 
statistics, t-tests, correlations, multivariate analysis of variance and covariance, and multiple linear regression. Findings are presented in the order of the research aims.

\section{Data Preparation}

Quantitative data were coded within the Qualtrics software program. Age was collected as a continuous variable on the survey forms and was also organized into five categories for statistical analysis. States in which nurses practiced were organized into five categories and reported in the narrative. Stressor events specified on the IES were the only qualitative data collected and after examining for themes, were organized into 12 categories. Data were screened prior to analyses in order to address the issues of accuracy of data entry, missing data, and to determine if the data met the assumptions of multivariate analyses.

Data entry. Coded data from the Qualtrics software program were imported into SPSS Version 17 (2008) from the AACN nurses, Rural Nurse Managers, and BSNCompletion students. Information from the master's in nursing students' paper and pencil surveys was manually entered into the data file by the investigator. Screening and cleaning was then completed. When three consecutive random samples, each consisting of $10 \%$ of the records, were determined to be without error, the process was concluded. Values were examined to verify that all fell within the set range and that all mean scores were plausible.

Missing data. Of the 127 surveys completed, 96 participants completed both the MDS and IES. Data from the 25 participants who completed the MDS, but not the IES, were included in the analysis for Aim 1 (difference between intensity and frequency of 
moral distress), but not for Aims 2 or 3 which required IES data. One participant completed the MDS items for Intensity but not Frequency and was excluded from analysis. One participant did not specify their gender, one did not specify their age, one did not specify race, two did not identify whether or not they had worked in a critical care setting, and one did not identify work status (full time/part time/per diem). One participant responded to only 3 of the 10 demographic items (gender, age, race). The data for these participants were retained for analysis since missing data were minimal. Mean substitution was used for missing items on the MDS and IES which constituted $0.58 \%$ and $0.2 \%$ of the total items respectively.

Normality. Normality of the distribution of scores was determined by assessing histograms, Q-Q plots, and using the Explore option in the SPSS Descriptive Statistics menu. The Kolmogorov-Smirnov statistic assesses the normality of the distribution of scores, with a non-significant result indicating normality (Pallant, 2007). The results indicated that the scores for both the MDS and IES were normally distributed with significant values above 0.05 (range $=0.195$ to 0.200 ). Normal probability (Q-Q) plots chart the expected value from a normal distribution against the observed value for each score. A fairly straight line suggests a normal distribution. The observed and expected values on the Q-Q plots for this analysis showed a reasonably straight line for both scales. A slightly negative skew was noted for the IES intrusion subscale indicating that scores were higher on this measure.

Linearity. The linear relationship of variables was assessed by examining bivariate scatterplots. The relationship of moral distress and impact of event did not meet 
the assumption of linearity. There was a slightly moderate positive relationship between moral distress Intensity and moral distress Frequency, and a weak positive relationship between Avoidance and Intrusion on impact of event.

Homoscedasticity. Homoscedasticity was measured by Box's M test of the equality of covariance matrices. Box's M statistic tests the null hypothesis that the observed covariance matrices of the dependent variables are equal across groups. For the dependent variables of total moral distress and total impact of event, Box's M was 3.561 $(F=1.152, p=.327)$ indicating that the assumption of homoscedasticity was not violated. The results of these tests suggest that the data are normally distributed and meet the assumptions for multivariate analyses.

\section{Sample Characteristics and Demographic Data}

\section{Sampling Information}

Data collection began November 13, 2009 and ended February 27, 2010. Data were collected using either paper and pencil or online surveys. Two faculty members from the school of nursing from the private university distributed paper and pencil surveys to a convenience sample of students in the master's in nursing program. Surveys were precoded and distributed during class time. The faculty members left the room and student volunteers collected all of the anonymous surveys in an envelope. The envelope was returned to the faculty members who mailed the surveys to the researcher. Students were also given the option to participate in the study via the online survey. These students did not receive a paper survey. Four students contacted the researcher due to difficulty 
with accessing the online survey and were provided with a link to connect directly to the survey.

A random subset of 370 members was drawn from a random sample of 3,500 nurse members of AACN and was mailed invitations to participate in the study. A list of members was provided to the researcher by AACN. A convenience sample of 87 members of the Rural Nurse Managers Organization and 185 BSN-completion students were contacted via email and invited to participate in the study resulting in a total of 642 email solicitations. One hundred twenty-seven online surveys were returned resulting in a response rate of $20 \%$. Thirty-five of 40 paper and pencil surveys were returned for a response rate of $88 \%$. A total of 682 surveys were distributed, with 162 returned for a combined response rate for online and paper and pencil surveys of $24 \%$. Data from the paper and pencil surveys were manually added to the SPSS data set containing the online surveys. Only 96 of the 162 surveys contained complete data (59.25\%). All data were analyzed with SPSS statistical software, version 17 (Chicago, IL).

\section{Demographic Data}

Demographic data were analyzed using descriptive statistics. Females comprised $92 \%$ of the participants. Ninety-one percent of participants were Caucasian, $4 \%$ were Asian, 2\% were Hispanic/Latino, and 2\% were Black. Ages ranged from 24 to 64 years with a mean of 41 years. The majority of participants $(n=52)$ held a baccalaureate degree in nursing, followed by associate degree $(n=21)$, master's $(n=12)$, diploma $(n=$ 5), degree in field other than nursing $(n=4)$ and doctorate $(n=1)$. Years that participants worked as an RN ranged from 1-2 $(n=10)$ years to more than 30 years $(n=13)$. Nurses 
with current or past critical care nursing experience comprised $70 \%(n=66)$ of the sample with $30 \%(n=28)$ reporting never having worked in critical care. Forty-five percent reported currently working in critical care. It was anticipated that gender and racial/ethnic characteristics of nurses in the study would resemble the population of nurses across the United States. Differences between the sample participants and the population of registered nurses in the U.S. are shown in Table 4.

Table 4

Comparison of Gender and Racial/Ethnic Characteristics of Sample Participants to US Population of Nurses

\begin{tabular}{lcc}
\hline \multicolumn{1}{c}{ Demographic } & $\begin{array}{c}\text { \% Study Participants } \\
n=96\end{array}$ & $\begin{array}{c}\text { \% US Population of } \\
\text { Nurses }\end{array}$ \\
\hline Gender & 92 & $93.9^{\mathrm{a}}$ \\
Females & 8 & $6.1^{\mathrm{a}}$ \\
Males & 91 & $83.2^{\mathrm{b}}$ \\
Race/Ethnicity & 2 & $5.4^{\mathrm{b}}$ \\
White & 4 & $5.8^{\mathrm{b}}$ \\
Black & 0 & $0.3^{\mathrm{b}}$ \\
Asian & 0 & $3.6^{\mathrm{b}}$ \\
Hawaiian/Pacific islander & 2 & $1.7^{\mathrm{b}}$ \\
American Indian/Alaska native & .01 & \\
Hispanic/Latino (any race) & & \\
Multiracial & &
\end{tabular}

Note. Statistics for US population of Asian and Hawaiian/Pacific islander nurses were combined in the 2008 survey.

${ }^{a}$ U.S. Department of Health and Human Services (n.d.).

${ }^{\mathrm{b}}$ U.S. Department of Health and Human Services (2010). 
Nurses stated that they had worked in their current position from $<1(n=8)$ to 30 years $(n=1)$. The highest proportion worked for $1-2$ years $(n=26)$ in their position.

Seventy-eight percent reported working full time (36+ hours/week), 18\% working part time and $4 \%$ per diem/casual. A majority of nurses $(n=56)$ reported working in two Midwestern states. The remainder worked in 16 other states $(n=26), 1$ in Europe, and 13 not reporting. No significant differences were found in demographic variables for those participants who completed and those who did not complete both the MDS and the IES (see Table 5).

Table 5

Demographic Characteristics for Participants Completing the MDS Only

\begin{tabular}{lccc}
\hline \multicolumn{1}{c}{ Variable } & $n$ & Test Statistic & p-value \\
\hline Gender & 120 & $X^{2}=0.00$ & 1.0 \\
Race/ethnicity & 120 & $X^{2}=1.89$ & 0.756 \\
$\begin{array}{l}\text { Highest level of education } \\
\text { Years worked as an RN }\end{array}$ & 120 & $X^{2}=6.31$ & 0.28 \\
$\begin{array}{l}\text { Years worked in critical } \\
\text { care }\end{array}$ & 119 & $X^{2}=6.98$ & 0.43 \\
$\begin{array}{l}\text { Current work in critical } \\
\text { care }\end{array}$ & 120 & $X^{2}=0.06$ & 0.2 \\
$\begin{array}{l}\text { Years worked in current } \\
\text { position }\end{array}$ & 120 & $X^{2}=3.9$ & 0.81 \\
$\begin{array}{l}\text { Full time/part time/per } \\
\text { diem }\end{array}$ & 119 & $X^{2}=3.13$ & 0.79 \\
\begin{tabular}{l} 
Age \\
\hline
\end{tabular} & 119 & $t=3.18$ & 0.21 \\
\hline
\end{tabular}


Critical care nurses and non-critical care nurses did not vary on demographic characteristics with the exception of age $(t=3.18, \mathrm{p}=.002)$ (see Table 6$)$. The mean age for critical care nurses and non-critical care nurses was $43(S D=11.2)$ and $35(S D=$ 11.74) respectively. This finding was unexpected as the literature reports that nurses desire a less intense work environment as they age (Tourangeau, Cummings, Cranley, Ferron, \& Harvey, 2010) and experience more physical and mental strain in their workplace (Buerhaus, 2009; Moseley, Jeffers, \& Paterson, 2008). Of note, for categorical variables, some cells had less than 5 values which may have impacted the ability to identify significant differences between groups.

Table 6

Demographic Data for Critical Care and non-Critical Care Nurses

\begin{tabular}{lccc}
\hline \multicolumn{1}{c}{ Variable } & $n$ & Test Statistic & p-value \\
\hline Gender & 95 & $X^{2}=0.48$ & 0.49 \\
Race/ethnicity & 95 & $X^{2}=9.02$ & 0.06 \\
Highest level of education & 95 & $X^{2}=6.59$ & 0.25 \\
Years worked as an RN & 95 & $X^{2}=21.4$ & 0.003 \\
Years worked in critical care & 94 & $X^{2}=94$. & $<0.001$ \\
Current work in critical care & 95 & $X^{2}=30.29$ & $<0.001$ \\
Years worked in current position & 95 & $X^{2}=12.04$ & 0.1 \\
Full time/part time/per diem & 94 & $X^{2}=1.32$ & 0.52 \\
Age & 95 & $t=3.12$ & 0.002 \\
\hline
\end{tabular}


Seventy-seven percent of participants completed the online survey and $23 \%$ the paper method. All those in the paper survey group were educated at the Bachelor's level and worked in Illinois. The majority of online participants were in the $40-49$ yrs $(n=22)$ and 50-59 yrs $(n=22)$ categories. The majority of participants taking the paper survey were in the 20-29 years age range $(n=14)$.

Significant differences were noted between survey method and race $\left(X^{2}(4, n=\right.$ $95)=11.37, p=.02$ ), with $80.2 \%$ of the online group being Caucasian while $19.8 \%$ of the paper method group being Caucasian. Significant differences were noted between survey method and highest level of education $\left(X^{2}(5, n=95)=23.68, p=.001\right)$ with all of the paper survey group being educated at the bachelor's level. Significant differences were also noted between survey method and years worked as an $\mathrm{RN}\left(X^{2}(7, n=95)=17.6, p=\right.$ $.01)$, having ever worked in a critical care setting $\left(X^{2}(1, n=96)=7.37, p=.007\right)$ and age $(t=(93)=5.36, p=.001)$. A plurality of online participants was concentrated in two age groups: 5-10 years $(n=13)$ and more than 30 years $(n=13)$. In the pencil survey group the majority were in the $1-2$ years $(n=6)$ and 5-10 years $(n=6)$ age ranges. No significant differences were found for years worked as an RN in critical care, current work in critical care, years worked in current position, or full time/part time status. Of note, for categorical variables, some cells had less than 5 values which may have impacted the ability to identify significant differences between groups. 


\section{Reliability and Validity of the MDS}

The MDS was developed to measure the Intensity and Frequency of moral distress of hospital nurses caring for adult populations. Results of the reliability and validity of the MDS subscales are presented.

\section{Reliability of the MDS}

Internal consistency reliability was computed for the MDS subscales of Intensity and Frequency using SPSS version 17 software (Chicago, IL). For group-level comparisons, Polit (2010) suggests that coefficients of 0.70 to 0.75 are adequate, but coefficients of 0.80 or greater are desirable. Reliability coefficients for this study are reported in Table 7. Analyzing item-total correlations revealed that the alpha would not have improved had any items from the instrument been removed.

Table 7

Reliability Coefficients for the MDS and IES in this Study Scale Cronbach's Coefficient Alpha

\begin{tabular}{ll}
\hline Moral Distress & \\
Intensity subscale & 0.97 \\
Frequency subscale & 0.89 \\
Impact of Event & \\
$\quad$ Avoidance subscale (Items $2,3,7,8,9,12,13,15)$ & 0.84 \\
Intrusion subscale (Items $1,4,5,6,10,11,14)$ & 0.88 \\
Total Instrument & 0.89 \\
\hline
\end{tabular}




\section{Validity of the MDS}

As discussed in Chapter Three, content validity of the MDS was supported by a review of the literature and by three doctorally prepared experts with nursing ethics research experience (Corley et al., 2005). Validity of the MDS was not assessed in this study.

\section{Reliability and Validity of the IES}

The IES was originally developed for use in the population of bereaved individuals, but has been most widely used as a measure of stress reactions after traumatic events, particularly for those experiencing post-traumatic stress disorder. A review of the psychometric properties of the scale, reported in studies over more than 20 years, has supported the reliability and validity of the instrument. Its' two-factor structure (avoidance and intrusion) has been shown to be stable for a variety of stressful events (Sunden \& Horowitz, 2002). Results of the reliability and validity of the IES for this study are presented here.

\section{Reliability of the IES}

Internal consistency reliability was computed for the IES total scale and subscales of Avoidance and Intrusion. Reliability coefficients for this study are reported in Table 7. Analyzing item-total correlations revealed that the alpha would not have improved had any items from the instrument been removed.

\section{Validity of the IES}

As discussed in Chapter Three, the IES has been shown to be valid and have adequate test-retest results. Validity of the IES was not assessed in this study. 


\section{Alpha Level, Power, and Effect Size}

An alpha level of 0.05 was selected as the significance level for all statistical tests. Effect sizes were computed by calculating the difference in mean scores divided by the pooled standard deviation. For Aim 1, a sample of 64 in each group was needed to achieve $80 \%$ power to detect a difference in mean scores on the MDS (t statistic) with a

medium effect size using Cohen's (1969) classification $(\mathrm{d}=.50)$. For Aim 2, a sample of 85 in each group was needed in order to achieve $80 \%$ power to detect correlations between MDS scores and IES scores ( $r$ statistic) with a medium effect size of $(r=.30)$. For Aim 3, a sample of 63 per group was needed $(n=126)$ in order to achieve $80 \%$ power to detect differences in mean scores on the MDS and IES after adjusting for age with a medium effect size $\left(\mathrm{f}^{2}=.50\right)$.

\section{Moral Distress and Avoidance Behavior in Nurses Working in Critical Care and non-Critical Care Settings}

The following are presentations of findings related to the three primary research aims.

\section{Aim 1a}

To determine if there was a difference between the intensity and frequency of moral distress of nurses in critical care and non-critical care settings: The independent variable was critical care status (critical care/non-critical care) and the dependent variables were MDS scores. The MDS contains two subscales: moral distress Intensity and moral distress Frequency. Both subscales are measured on an ordinal level from 0 to 6. Zero indicates that the participant did not have experience with the situation described 
in the particular item. For the Intensity subscale, 6 represents to a "great extent." For the Frequency subscale, 6 represents "very frequently." Total moral distress scores range from 0-456 (0-228 each for Intensity and Frequency). Scores for this sample ranged from 1 to 307 .

Differences in moral distress scores across groups. An independent-samples ttest was conducted to compare the total moral distress scores for critical care and noncritical care nurses. Mean moral distress score for the critical care nurses $(M=229.71$, $S D=71.26)$ was higher than the score for non-critical care nurses $(M=209.07, S D=$ 68.25), however the difference was not statistically significant $(t(94)=1.31, p=0.25)$. Effect size $(d=0.296)$ was small and may be partially explained by small sample size. A priori power analysis for Aim 1 indicated that 64 participants per group were needed to have $80 \%$ power to detect a difference in mean MDS scores. Only 96 complete data sets were available to evaluate this aim.

An independent-samples t-test was conducted to compare moral distress Intensity scores for critical care and non-critical care nurses. Total scores for critical care nurses $(M=143.99, S D=57.45)$ were higher than for non-critical care nurses $(M=129.21, S D$ $=54.48)$, however, the difference was not statistically significant $(t(94)=1.16, p=0.25)$. Effect size $(\mathrm{d}=0.264)$ was small.

An independent-samples t-test was conducted to compare moral distress Frequency scores for critical care and non- critical care nurses. Critical care nurses reported a higher Frequency of moral distress $(M=85.71, S D=23.42)$ compared to non- 
critical care nurses $(M=79.86, S D=20.37)$, but the difference was not statistically significant $(t(94)=1.16, p=0.25)$. Effect size $(\mathrm{d}=0.266)$ was small.

The item with the lowest total score for MD Frequency was item 29, "Respond to a patient's request for assistance with suicide when patient has a poor prognosis" $(M=$ $1.09, S D=0.28)$. There was a very small difference in the mean scores for Frequency between critical care nurses $(M=1.10, S D=0.35)$ and non- critical care nurses $(M=$ $1.11, S D=0.57)$ for this item, but the difference was not statistically significant $(t(94)=$ $-.04, p=0.97)$. Effect size $(\mathrm{d}=0.036)$ was very small.

The item with the highest total score for MD Frequency was item three, "Carry out a physician's order for unnecessary tests and treatment" $(M=4.13, S D=2.11)$. Critical care nurses had a lower score for Frequency $(M=3.72, S D=1.71)$ than noncritical care nurses $(M=4.0, S D=1.41)$ for this item, but the difference was not significant $(t(94)=-.77, p=0.45)$. Effect size $(d=0.213)$ was small.

The item with the lowest total score for MD Intensity was item 11, "Assist physicians who are practicing procedures on a patient after CPR has been unsuccessful" $(M=2.04, S D=2.03)$. Critical care nurses had a higher score $(M=2.63, S D=2.33)$ than non-critical care nurses $(M=2.0, S D=1.92)$ for this item, but the difference was not significant $(t(94)=1.37, p=0.18)$. Effect size $(d=0.295)$ was small. The item with the highest total score for MD Intensity was number five, "Initiate extensive life-saving actions when I think it only prolongs death" $(M=5.0, S D=1.81)$. Critical care nurses had a higher score $(M=4.80, S D=1.97)$ than non- critical care nurses $(M=3.86, S D=$ 
2.15). A $t$-test showed a significant difference in scores for these two groups on this item $(t(94)=2.073, p=.04)$. A medium effect size was detected $(d=0.456)$.

An independent-samples t-test was conducted to compare the total moral distress scores for the online participants and those who completed the paper survey. Mean moral distress score for online participants $(M=225.08, S D=73.81)$ was higher than the score for paper and pencil participants $(M=219.02, S D=60.27)$, however the difference was not statistically significant $(t(94)=.351, p=0.73)$. Effect size $(\mathrm{d}=0.09)$ was small.

\section{Aim 1b}

To determine if there was a difference in mean Moral Distress Scale and Impact of Event Scale scores between critical care and non-critical care nurses and to determine if there was a difference after adjusting for age. The independent variable was critical care work status, the dependent variables were MDS and IES scores, and age was the covariate.

\section{Difference in moral distress and avoidance scores across groups. A one-way}

between groups multivariate analysis of variance was performed to investigate differences in mean Moral Distress Scale and Impact of Event Scale scores between critical care and non-critical care nurses. Box's M test showed that the assumption of homogeneity of variance-covariance matrices was not violated, $M=.321$. The significance value for Levene's test was $\mathrm{p}=0.375$ for moral distress and $\mathrm{p}=0.223$ for impact of event showing no violation of the assumption of equality of variance for both variables. There was no significant difference between critical care nurses and noncritical care nurses on Moral Distress Scale and Impact of Events Scale scores; F(2, 93) = 
$2.19, \mathrm{p}=.12$. While there was no significant difference in scores, critical care nurses reported higher levels of moral distress $(\mathrm{M}=229.72, \mathrm{SD}=71.27)$ than non-critical care nurses $(M=209.07, \mathrm{SD}=68.26)$. Non-critical care nurses reported higher levels of avoidance behavior $(M=54.05, S D=14.84)$ than critical care nurses $(M=49.64, S D$ $=12.8$ ).

A one-way between groups multivariate analysis of variance was performed to investigate differences in mean Moral Distress Scale and Impact of Event Scale scores between online and paper survey participants. There was a significant difference between online and paper and pencil participants on Moral Distress Scale and Impact of Event Scale scores; $\mathrm{F}(2,94)=3.35, \mathrm{p}=.04$.

\section{Difference in moral distress and avoidance scores across groups after}

adjusting for age. A one-way between groups analysis of covariance was conducted to compare the differences in mean Moral Distress Scale and Impact of Event Scale scores between critical care and non-critical care nurses after adjusting for age. Box's M test showed that the assumption of homogeneity of variance-covariance matrices was not violated, $M=0.327$. The significance value for Levene's test was $\mathrm{p}=0.436$ for moral distress and $p=0.215$ for impact of event showing no violation of the assumption of equality of covariance for both variables. After adjusting for age, there was no significant difference between critical care nurses and non-critical care nurses on Moral Distress Scale $(F(1,92)=.892, p=.347)$ and Impact of Events Scale scores $(F(1,92)=3.801, p$ $=.054)$. 
$\operatorname{Aim} 2$

To determine if there was a correlation between moral distress and avoidance behaviors in critical care and non-critical care nurses:

\section{Correlation between moral distress and avoidance thoughts and behaviors.}

It was hypothesized, based on the literature that repeated exposures to morally distressing situations would be associated with avoidance thoughts and behaviors. Avoidance was measured using the IES. The IES is a 15-item instrument that contains two subscales; Avoidance (8 items) and Intrusion (7 items). Participants are asked to identify a stressor event in their life and how long ago the event occurred. The scales are measured with a Likert type scale ranging from 0 to 5 . Zero indicates that the item did not occur, $1=$ rarely, $3=$ sometimes, and $5=$ often. Numbers 2 and 4 are not labeled. An analysis using Pearson product-moment correlation coefficient showed a small positive correlation between moral distress and avoidance that was not statistically significant $(r=0.107, n=$ $96, p=.298)$.

Identification of a stressor event. The IES begins with an open-ended question asking participants to write in "the stressor event in your life that the following items will refer to". Participants are then prompted to indicate in days, weeks, months, or years how long ago the event occurred. Constant comparison of the data generated from this question was conducted during the data collection period and analysis. Data reduction occurred as new data were collected and common themes thought to best represent the participant's thoughts and feelings about their stressor events were identified. New categories and labels were added as analyses progressed (see Table 8). Time since an 
event occurred ranged from 1-6 days $(n=18), 1.5-3$ weeks $(n=6), 1-11$ months $(n=26)$, and 1-30 years $(n=41)$. One participant reported the event occurred 'constantly'. Eight participants did not identify an event, but did respond to each of the 15 items on the scale.

Table 8

Stressor Life Events and Times Identified on IES

\begin{tabular}{|l|c|}
\hline \multicolumn{1}{|c|}{ Category } & \# of Occurrences \\
\hline Work-related & 18 \\
\hline Miscellaneous & 10 \\
\hline End-of-life & 5 \\
\hline Questioning competence of colleagues & 3 \\
\hline Uncontrolled/unrelieved patient pain/suffering & 1 \\
\hline Surgery on patient without informed consent & 10 \\
\hline Death in family & 10 \\
\hline Financial & 9 \\
\hline Relationships/divorce/abuse & 9 \\
\hline Health issues in family & 7 \\
\hline Murder/suicide/crime & 2 \\
\hline Death of pet & 3 \\
\hline $\begin{array}{l}\text { Other "going back to school for my master's"; "moving"; } \\
\text { "school" }\end{array}$ & \\
\hline
\end{tabular}

Differences in IES scores across groups. An independent-samples t-test was conducted to compare the total IES scores for critical care and non-critical care nurses. 
Mean scores for the critical care nurses $(M=37.33, S D=13.53)$ were less than the scores for non-critical care nurses $(M=41.98, S D=15.97)$, however the difference was not statistically significant $(t(94)=-1.45, p=0.15)$. Effect size for the difference between groups $(d=0.314)$ was small. Likewise, mean scores on the IES Avoidance subscale for critical care nurses $(M=16.12, S D=7.54)$ were less than for non-critical care nurses $(M$ $=19.56, S D=10.49)$ and showed no significant difference $(t(94)=1.57, p=0.12)$. Effect size for differences between groups on the avoidance subscale $(d=0.377)$ was moderately small. Mean scores on the IES Intrusion subscale for critical care nurses $(M=$ 21.20, $S D=8.11)$ were slightly less than for non-critical care nurses $(M=22.42, S D=$ 8.29) and showed no significant difference $(t(94)=-.67, p=0.51)$. Effect size $(d=$ 0.149) was small.

The item with the highest score for the total IES was number 1, "I thought about it when I didn't mean to" $(M=3.91, S D=1.19)$. There was a very small difference in the mean scores between critical care nurses $(M=3.91, S D=1.25)$ and non-critical care nurses $(M=3.92, S D=1.05)$ for this item $(t(94)=-.039, p=0.969)$. As expected, the effect size was negligible $(\mathrm{d}=0.009)$. The lowest scoring item for the total IES was number 8 , "I felt as if it hadn't happened or wasn't real" $(M=1.58, S D=1.68)$. There was a difference in the mean scores between critical care nurses $(M=1.29, S D=1.54)$ and non-critical care nurses $(M=2.29, S D=1.82)$ for this item $(t(94)=-2.72, p=0.008$. A medium effect size of 0.593 was detected.

An independent-samples t-test was conducted to compare the total IES scores for online and paper survey participants. Mean scores for the online participants $(M=52.82$, 
$S D=12.93)$ were greater than the scores for paper participants $(M=44.54, S D=13.71)$.

The difference was statistically significant $(t(94)=2.6, p=0.01)$. Effect size for the difference between groups $(\mathrm{d}=0.621)$ was moderate.

\section{Aim 3}

To determine if there was a relationship between moral distress and avoidance behaviors in critical care and non-critical care nurses after adjusting for age:

Difference between MD and IES after adjusting for age. A multivariate analysis of covariance was conducted to determine if there was a difference between moral distress and avoidance thoughts and behaviors by nurses after adjusting for age. With Levene's test significance values of $\mathrm{p}=0.436$ and $\mathrm{p}=0.215$ for total moral distress and total impact of event respectively, the assumption of equality of variances was not violated. With unequal sample sizes, Polit (2010) suggests using the Box $M$ test to assess homogeneity. The results for this analysis were Box's $M=3.561, F=1.15$, and $p=.327$. After adjusting for age, there was no statistically significant difference between the two groups on moral distress $(F(1,92)=.89, p=.35)$ or impact of event $(F(1,92)=3.80, p=$ $.05)$ scores.

\section{Summary of Findings}

Results of the data analyses are reported in this chapter. Data preparation included assessing accuracy of data entry, assessment of missing data, and determination of normality, linearity, and homoscedasticity. Sample characteristics and demographic data were reported. The sample was homogeneous with the majority being female (92\%) and white $(91 \%)$. There was a significant difference between critical care and non- critical 
care nurses in age, but there were no differences for other demographic variables. Internal consistency reliability of the MDS and IES instruments were evaluated and found to be strong with Cronbach's alphas ranging from 0.84 to 0.97 .

Although critical care nurses had higher total mean MDS scores than non-critical care nurses, the difference was not statistically significant. Scores for the subscales of Intensity and Frequency also showed no statistically significant differences across groups. Analysis of the relationship between moral distress and avoidance showed a very small positive correlation, but was not statistically significant. Twelve different categories of stressor life events were reported by participants who completed the IES. Scores for the total IES, as well as the Avoidance and Intrusion subscales, were all somewhat lower for critical care nurses compared to non- critical care nurses but these results were not statistically significant. After adjusting for age, there was no statistically significant difference between the groups on MDS or IES scores. 


\section{CHAPTER FIVE}

\section{DISCUSSION}

The interpretation of findings is discussed in this chapter. Discussion includes relationships between moral distress and avoidance behaviors, as well as implications for nursing, strengths and limitations of the study, and recommendations for future research.

\section{Aims of the Study}

Moral distress continues to be reported by nurses practicing in both critical care and non-critical care settings. While it was anticipated that nurses working in critical care settings would experience more moral distress than those in non-critical care settings, the results of this study showed that total mean scores on the MDS were not significantly different for the two groups; nor were scores on the subscales of Intensity and Frequency. Bivariate analysis of age, gender, and race showed that only age was significantly different between critical care nurses and non-critical care nurse participants, therefore, gender and race were not considered for further analyses. After adjusting for age, there was no statistically significant difference between moral distress and avoidance behaviors for the two groups.

\section{Aim 1a: Differences in MDS Scores}

While mean MD scores did not vary between groups, there was a significant difference in scores between critical care nurses and non-critical care nurses in instances of initiating life-saving measures which may prolong death. This may be accounted for 
due to the life-threatening illnesses of patients cared for in critical care settings. Nurses in non-critical care settings may not have the responsibility of initiating extensive lifesaving measures due to the lower acuity level of patients in their care. This may also be a limitation of the MDS instrument for use in non-critical care settings. Working with nurses who were not as competent as the participants believed they should be was a highscoring event. A possible explanation for this result was not found in the literature but holds implications for all stakeholders involved. The safety and well-being of patients is threatened if nurse competencies are inadequate. There are negative implications for colleagues as well who may feel an additional burden for patients or may experience anxiety, moral distress, or physical symptoms associated with working under these conditions.

Carrying out orders for unnecessary tests and treatments, and following families' wishes to continue life support that was not believed to be in the best interests of the patient were the most frequently occurring events. Similar results were found by Fogel (2007), with "continuing life support when not in the best interests of the patient" being the highest scoring item in that study. This item had the highest Frequency score in the current study and showed a significant difference in the mean scores between critical care and non-critical care nurses. It is likely that nurses in non-critical care settings do not care for patients on life support, reflecting the lower mean scores for this item for that group.

\section{Aim 1b: Differences in IES Scores}

It was anticipated that nurses would identify a stressor event from their nursing practice when completing the IES. However, of 87 identified events, 50 (57\%) were not work-related. Responses to items on this scale may have been rated differently had they 
been specified as work-related events. In turn, this may have influenced the results of scores on the IES and the relationship between moral distress and avoidance in nursing practice settings. Both groups of nurses reported high scores for "thinking about a stressor event when they did not mean to". This reflects the intrusive nature and unintentional remembering of stressful events. There was a significant difference between critical care and non-critical care nurses for "feeling as if an event had not happened or was not real", even though this was the lowest scoring item on the instrument. It may be that critical care nurses' frequent exposure to stressful events increases their awareness of the realities that are an infrequent occurrence for non-critical care nurses.

\section{Aim 2: Correlation Between Moral Distress and Avoidance Thoughts and Behaviors}

Avoidance thoughts and behaviors were reported by participants, but were not significantly correlated with moral distress. This may be partially explained by the fact that most participants did not identify a stressor event that was related to their work setting, or it may have been an event that was stressful, but not morally distressing. For instance, two participants with high scores on the Avoidance subscale identified their stressor events as 'being accused of sexual assault by a confused patient', and 'being accused of something that was not true'. These types of events may not have been morally distressing to the participant, but were given the highest possible rating on item number 13 on the IES, 'I tried not to think about it'. While nurses may experience moral distress, they may not identify it as such. As well, it may be that the IES is not an effective measure of the avoidance nurses engage in as part of the moral distress experience. 


\section{Aim 3: Relationship Between Moral Distress and Avoidance Thoughts and Behaviors After Adjusting for Age}

While there was no significant difference between moral distress and avoidance behaviors in critical care and non-critical care nurses after adjusting for age, critical care nurses were significantly older than non-critical care nurses. The disproportionate number of critical care nurses may have impacted the ability to detect a difference between the two groups. Gender and race were not considered to be possible confounders as the bivariate testing showed no significant difference between the two groups of nurses for those variables.

\section{Lack of Power}

Polit (2010) suggests that the risk of a Type II error (concluding that a relationship does not exist when in fact it does) can be decreased by an adequate sample size and assuring adequate power. All aims for this study sought to achieve $80 \%$ power, but sample size was not sufficient to achieve this end. Aim 1 required 64 participants in each group, Aim 2 required 85 participants per group, and Aim 3 required 63 participants per group. The first recruitment letters were sent via email between November $13^{\text {th }}$ and $15^{\text {th }}$ to the BSN-Completion students and the rural nurse managers. Due to University directive, follow-up contact with the BSN-Completion students in the form of reminder emails or postcards was prohibited. The member list from AACN was received on December 3, 2009 after which time 210 recruitment letters were sent via US postal mail. As few surveys had been received by the end of December, an additional mailing was sent out to the AACN group on December $28^{\text {th }}, 2009$. To further increase the response rate, a third mailing to this group was sent on January $9^{\text {th }}, 2010$. In addition, a final 
attempt to increase the sample size and response rate was undertaken by soliciting participation from campus nursing students in a face-to-face setting. The paper and pencil surveys were returned on February 11, 2010. A total of 682 invitations to participate were sent via email, US postal service, and via face-to-face solicitation in the classroom setting. Despite efforts to recruit a large enough sample size to assure adequate power, there was an unexpectedly low return rate of 127 online (20\% response rate) and 35 paper and pencil ( $88 \%$ response rate) surveys for a combined overall response rate of $24 \%$. Sixty-six surveys were excluded from analyses due to failure to complete the IES; resulting in 96 complete data sets.

\section{Disproportionate Number of Critical Care Nurses}

Lack of statistically significant results may be partially explained by a disproportionate number of nurses in the critical care group (critical care nurses $n=68$, non- critical care nurses $n=28$ ). A more equal distribution of critical care and noncritical care nurses through purposive sampling was anticipated. AACN members would comprise the group of critical care nurses while BSN completion and master's students, and members of the Rural Nurse Manager's Organization were expected to comprise the group of non-critical care nurses. To assure an adequate proportion of critical care nurse participants, members of AACN were purposively sampled. While the sample of critical care nurses was sufficient for Aims 1 and 3, it fell short by 17 participants to be adequate for Aim 2. The non-critical care nurses made up only $29 \%$ of the sample and their numbers were not sufficient to meet any of the 3 aims.

It is not known how many non-critical care nurses comprised the non-AACN member groups. There may have been a larger number of critical care nurses among the 
rural nurse managers and the nursing students than anticipated, resulting in a lower proportion of non-critical care nurses available for the study. These factors may all have contributed to insufficient power for this study. Determining the proportion of critical care nurses in the general population and drawing proportionately from a medicalsurgical nursing group may have resulted in more equitable groups and enhanced power.

\section{Small Effect Sizes}

Effect size is a measure of the strength of a relationship between variables and adds to the researcher's knowledge beyond knowing that there is a relationship (Polit, 2010). Effect sizes in this study ranged from negligible to moderate but most were small. We hypothesized that scores on the MDS and IES would vary significantly between critical care and non-critical care nurses. However, the magnitude of the differences in scores was small. This is most likely a result of a small, homogeneous sample and lack of power to detect significant differences. There may be other variables which explain moral distress and avoidance behaviors that were not measured in this study. For instance, although not examined in this study, Corley's theory acknowledges institutional constraints as a component of moral distress. Olson (1998) proposed nurses experience decreased levels of moral distress when they have good relationships with managers, physicians, and administration. Work environment and relationships were not examined in this study. While demographics were similar between nurses in this study and those in the US population, this convenience sample may not represent the population of critical care and non-critical care nurses in the US. Additionally, this study had a larger percentage $(91 \%)$ of Caucasian nurses compared to the US national percentage $(83.2 \%)$. 
Blacks comprised only $2 \%$ of study participants. Corley et al. (2005) found that African American race was correlated with moral distress intensity. It may be that a larger proportion of African Americans in this study may have resulted in significant findings for some tests. The low response rate of the study resulted in a small sample size as well as a disproportionate number of critical care nurses versus non-critical care nurses.

\section{Reliability and Validity of the MDS and IES}

Reliability and validity of the MDS (Corley et al., 2001, 2005; Elpern et al., 2005; Meltzer \& Huckabay, 2004) and IES (Davis et al., 2005; Horowitz, Wilner, \& Alvarez, 1979; Horowitz et al., 2001; Sundin \& Horowitz, 2002) has been well-established in prior studies. Reliability analyses for this study showed the MDS and IES to have adequate internal consistency with Cronbach's alphas ranging from .84 to .97 . This study reaffirms the reliability of the MDS, however, validity was not measured in this study. Content and construct validity may not be supported in this sample of critical care nurses, nurse managers, and baccalaureate and graduate nursing students practicing in a variety of settings. Clinical practice and health systems have changed considerably since the MDS and the IES were designed and first tested. It is possible that they are no longer valid measures in the $21^{\text {st }}$ century.

\section{Implications for Nursing}

While the results of this study did not show a significant difference between moral distress and avoidance behavior in critical care and non-critical care nurses, scores on both instruments reflected that moral distress and avoidance do occur in nursing practice and that nurses are able to identify the intensity and frequency of morally 
distressing events. Events that were identified in Corley (1995) and Fogel's (2007) studies as occurring most frequently, such as "following family wishes to continue life support that is not in the best interest of the patient", and "carrying out physician's orders for unnecessary tests and treatments", were also the most frequently occurring events in this study. Initiating life-saving actions that prolong the dying process was the most frequently occurring event in Corley's study, and the event identified as having the highest intensity in the current study. Over the course of 15 years since Corley's study, the same events are being identified by nurses as being the most frequent and intense. This finding suggests that some items on the tool remain valid, at least in the population of critical care and non-critical care nurses tested by Corley.

Even though some participants did not identify a specific stressor event on the IES form, frequency of individual events was reported by respondents. More than $53 \%$ of items on the IES had mean scores falling above the mid-point of the scale. Not all stressful events had a high level of frequency, but the lasting effects of events are reflected in the time since occurrence identified by participants. More than $42 \%$ of participants who identified a stressor event, indicated the event had occurred more than a year ago and as long as 30 years ago. The mean length of time was 5.8 years. This type of lasting moral distress can lead to what Hardingham (2004) and Webster and Baylis (2000) describe as moral residue. This moral residue stems from instances of moral distress that were associated with compromising one's self or allowing others to be compromised. 
Nurses need to be able to express their experiences of moral distress and be supported in their efforts to alleviate its lasting effects. More research on moral distress in nursing is needed to identify (a) environmental and causative factors, (b) interventions that may mediate its impact on nurses, and (c) other populations of nurses that may experience this phenomenon, such as those in long-term care settings, emergency departments, and clinics. In addition, research is needed on how relationships with other health care providers may intensify or inhibit the negative effects of moral distress on nurses and patients. It is imperative that moral distress be recognized as a real problem for individual nurses and the profession. Researchers and administrators need to examine its impact on the psyche of nurses and on retention of nurses if we are to sustain and support the profession.

\section{Strengths of the Study}

While avoidance behavior has been reported in nurses working in critical care (Gutierrez, 2005), in clinics assisting with elective abortions (Hanna, 2005), in delivery rooms, gynecology units, emergency departments, surgery, operating rooms, and pediatrics (Kagan, Ovadia, \& Kanetai, 2009) and multi-service clinical units (medical, surgical, intensive care, oncology, mental health) (Lambert et al., 2007), this study was specifically focused on avoidance thoughts and behaviors and moral distress in critical care and non-critical care nurses. This area has not been well-studied and the data from this study contributes to what is known about the concept of avoidance as it relates to moral distress in these populations of nurses. The study was innovative in using a 
predominantly online format for data collection to assess moral distress. The study drew from the population of nurses across the United States.

\section{Limitations of the Study}

The greatest limitation was lack of power to detect between group differences in MD and avoidance thoughts and behaviors. Six hundred-eighty-two nurses were invited to participate in the study. Only 162 surveys were returned for a $24 \%$ response rate. Only 96 of the 162 surveys contained complete data (59.25\%). Responders who completed the MDS, but not the IES, were eliminated from the analysis, resulting in only 96 complete surveys for analyses. Some participants did not specify the nature of the stressor event that the items on the IES tool related to. In this case, conducting the surveys in person or providing more comprehensive directions may have reduced the number of nonresponders to the IES.

Sampling bias may be a limitation in this study. Participants who were solicited online via email may have been more inclined to report sensitive information, such as moral distress and stressor events, in the anonymity of a secure Internet site. However, the response rate was higher from those nurses who completed the paper and pencil survey in a classroom setting. Perhaps the presence of other nurses in the room or how the request to participate was presented to the students by nursing faculty influenced the participants' willingness to complete the survey.

In an effort to closely approximate characteristics of the population of critical care nurses, members of AACN were solicited to participate. It was anticipated that the remainder of the sample would provide a sufficient number of non-critical care nurses to 
comprise an approximately equal number of participants in each group. Subsequently, the large number of nurses solicited from AACN resulted in a disproportionate number of critical care nurses and may have contributed to the lack of statistically significant differences in MD and avoidance thoughts and behaviors between groups.

Some participants had difficulty with the link to the online survey and emailed the investigator. A response email was sent to these nurses with a link they could either click on to activate or copy and paste into a browser. Some potential participants may have chosen to opt out of completing the survey if they encountered a problem with the link and were unable to connect to the survey on the first attempt. AACN members had to manually insert the website address into a browser to connect to the online survey site. This may have resulted in incorrectly entered characters and failure to connect. These nurses may have chosen not to participate.

Finally, the sample was homogeneous; 92\% female and 91\% Caucasian. It would have been desirable to have a more heterogeneous sample; however the participants in this study resembled the population of nurses across the United States which is $93.9 \%$ female and $83.2 \%$ Caucasian.

\section{Recommendations for Future Research}

Replication of this study with a larger, more heterogeneous sample and equal numbers of critical care and non-critical care nurses would be desirable. Other populations of nurses, such as those practicing in long-term care, dialysis, and hospice settings could be investigated for their experiences with moral distress and avoidance behaviors. It would be of interest to examine nurse managers' experiences of moral 
distress and their participation in supporting nurses exposed to moral distress on a routine basis in their practice settings. The effects of nurses' moral distress and avoidance thoughts and behaviors on patients and the provision of their care need to be studied. Additionally, moral distress in patients and family members could be examined.

Other factors that may contribute to the experience of moral distress and avoidance behaviors could be explored, such as level of nursing education, previous ethics education, membership on an ethics committee, spirituality, perceived support received from peers and nurse managers, or employment in faith-based and public health care institutions. Qualitative inquiry, or a mixed-methods approach combining qualitative interviews and quantitative instruments, may provide rich data that might not be obtained with a self-administered instrument alone.

\section{Summary of the Discussion}

In summary, the purpose of this study was to explore the relationships between moral distress and avoidance thoughts and behaviors between nurses currently practicing in critical care and non-critical care settings and to determine if a relationship remained after adjusting for age. Significant findings included: 1) moral distress and avoidance behaviors are present in nurses practicing in critical care and non-critical care settings; 2) mean total moral distress scores, as well as Intensity and Frequency of moral distress were higher for critical care nurses, but lack of power may have precluded establishing statistical significance; 3) avoidance thoughts and behaviors were not significantly correlated to moral distress; 4) there was no significant relationship between moral distress and avoidance after adjusting for age; 5) the most frequent event causing moral 
distress for critical care nurses was following a family's wishes for continued life support when it was perceived by the nurse not to be in the best interests of the patient; the most frequent event for non-critical care nurses was carrying out a physician's order for tests and treatments that were felt to be unnecessary; 6) the item with the highest mean score for intensity of moral distress for critical care nurses was working with nurses who are perceived to not be as competent as the patient's care requires; for non-critical care nurses working with levels of nurse staffing that was considered unsafe had the highest mean moral distress intensity score. 
APPENDIX A

MORAL DISTRESS SCALE 
Moral Distress is defined as a painful feeling and/or psychological disequilibrium caused by a situation where:

1) you believe you know the ethically appropriate action to take, and

2) you believe you cannot carry out that action because of institutionalized obstacles, such as lack of time, supervisory disinterest, medical power, institution policy or legal limits.

This scale measures your perceptions on two dimensions: 1) level of moral distress, and 2) frequency of this situation.

The following situations occur in clinical practice. These situations may or may not cause moral problems for you.

For your current position, please indicate for each of the following situations, the extent to which you experience MORAL DISTRESS and its FREQUENCY. If you do not have experience with the situation, please indicate 0 in both columns. Please answer by checking the appropriate column for each dimension.

\begin{tabular}{|c|c|c|c|c|c|c|c|c|c|c|c|c|c|c|c|}
\hline & & \multicolumn{14}{|c|}{ Moral Distress } \\
\hline & & \multicolumn{7}{|c|}{ Intensity } & \multicolumn{7}{|c|}{ Frequency } \\
\hline & & \multicolumn{3}{|c|}{ None } & \multicolumn{4}{|c|}{ Great extent } & \multicolumn{3}{|c|}{ Never } & \multicolumn{4}{|c|}{ Very frequently } \\
\hline & & 0 & 1 & 2 & 3 & 4 & 5 & 6 & 0 & 1 & 2 & 3 & 4 & 5 & 6 \\
\hline 01 & $\begin{array}{l}\text { 1. Follow the family's wishes for the patient's } \\
\text { care when I do not agree with them but do so } \\
\text { because hospital administration fears a } \\
\text { lawsuit. }\end{array}$ & & & & & & & & & & & & & & \\
\hline 02 & $\begin{array}{l}\text { 2. Follow the family's wishes to continue life } \\
\text { support even though it is not in the best } \\
\text { interest of the patient. }\end{array}$ & & & & & & & & & & & & & & \\
\hline 03 & $\begin{array}{l}\text { 3. Carry out a physician's order for } \\
\text { unnecessary tests and treatment. }\end{array}$ & & & & & & & & & & & & & & \\
\hline 04 & $\begin{array}{l}\text { 4. Assist a physician who performs a test or } \\
\text { treatment without informed consent. }\end{array}$ & & & & & & & & & & & & & & \\
\hline 05 & $\begin{array}{l}\text { 5. Initiate extensive life-saving actions when } \\
\text { I think it only prolongs death. }\end{array}$ & & & & & & & & & & & & & & \\
\hline 06 & $\begin{array}{l}\text { 6. Ignore situations of suspected patient abuse } \\
\text { by caregivers. }\end{array}$ & & & & & & & & & & & & & & \\
\hline 07 & $\begin{array}{l}\text { 7. Ignore situations in which patients have not } \\
\text { been given adequate information to insure } \\
\text { informed consent. }\end{array}$ & & & & & & & & & & & & & & \\
\hline 08 & $\begin{array}{l}\text { 8. Carry out a work assignment in which I do } \\
\text { not feel professionally competent. }\end{array}$ & & & & & & & & & & & & & & \\
\hline 09 & $\begin{array}{l}\text { 9. Avoid taking action when I learn that a } \\
\text { nurse colleague has made a medication error } \\
\text { and does not report it. }\end{array}$ & & & & & & & & & & & & & & \\
\hline 10 & $\begin{array}{l}\text { 10. Let medical students perform painful } \\
\text { procedures on patients solely to increase their } \\
\text { skill. }\end{array}$ & & & & & & & & & & & & & & \\
\hline 11 & $\begin{array}{l}\text { 11. Assist physicians who are practicing } \\
\text { procedures on a patient after CPR has been } \\
\text { unsuccessful. }\end{array}$ & & & & & & & & & & & & & & \\
\hline
\end{tabular}




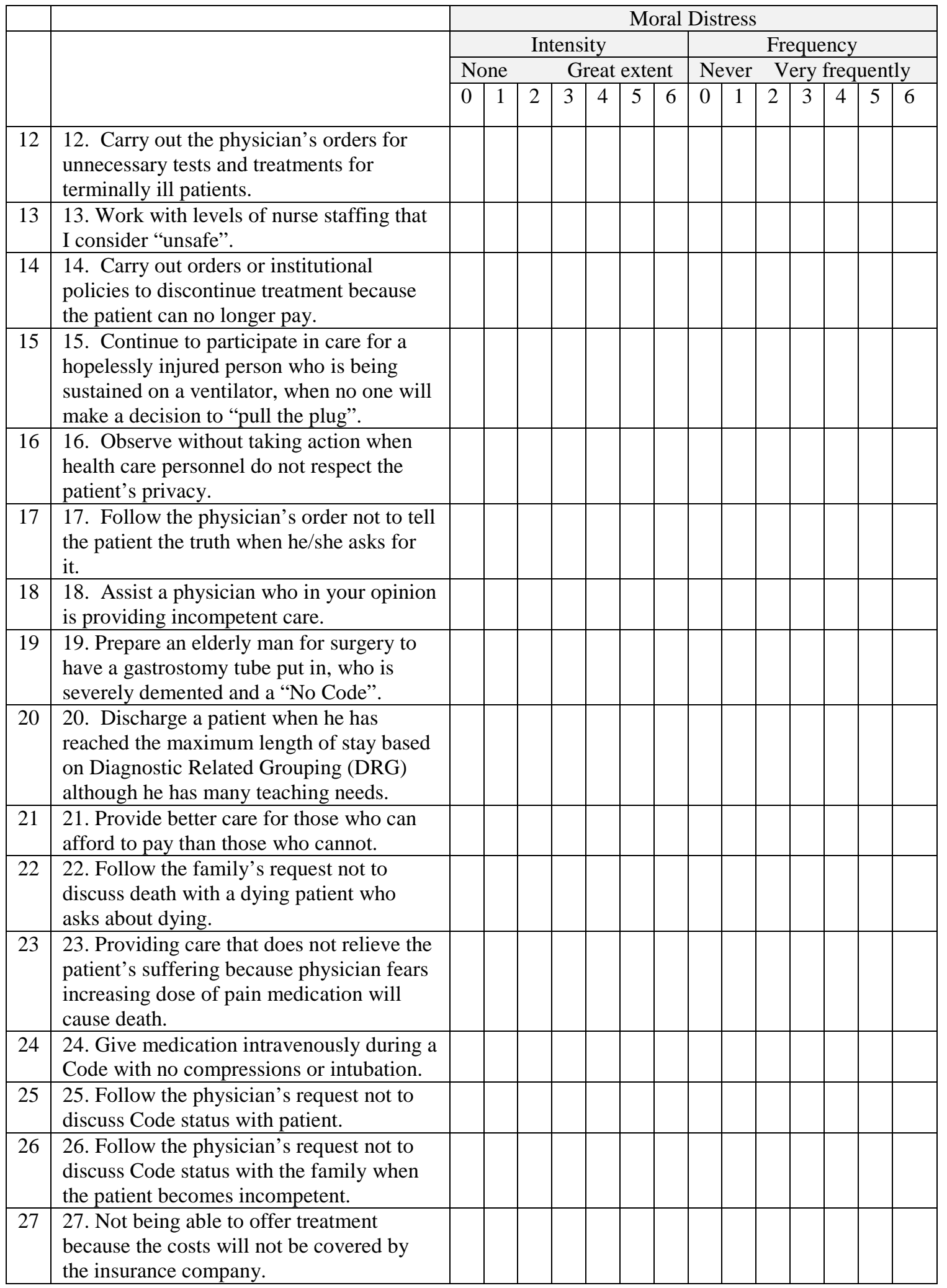




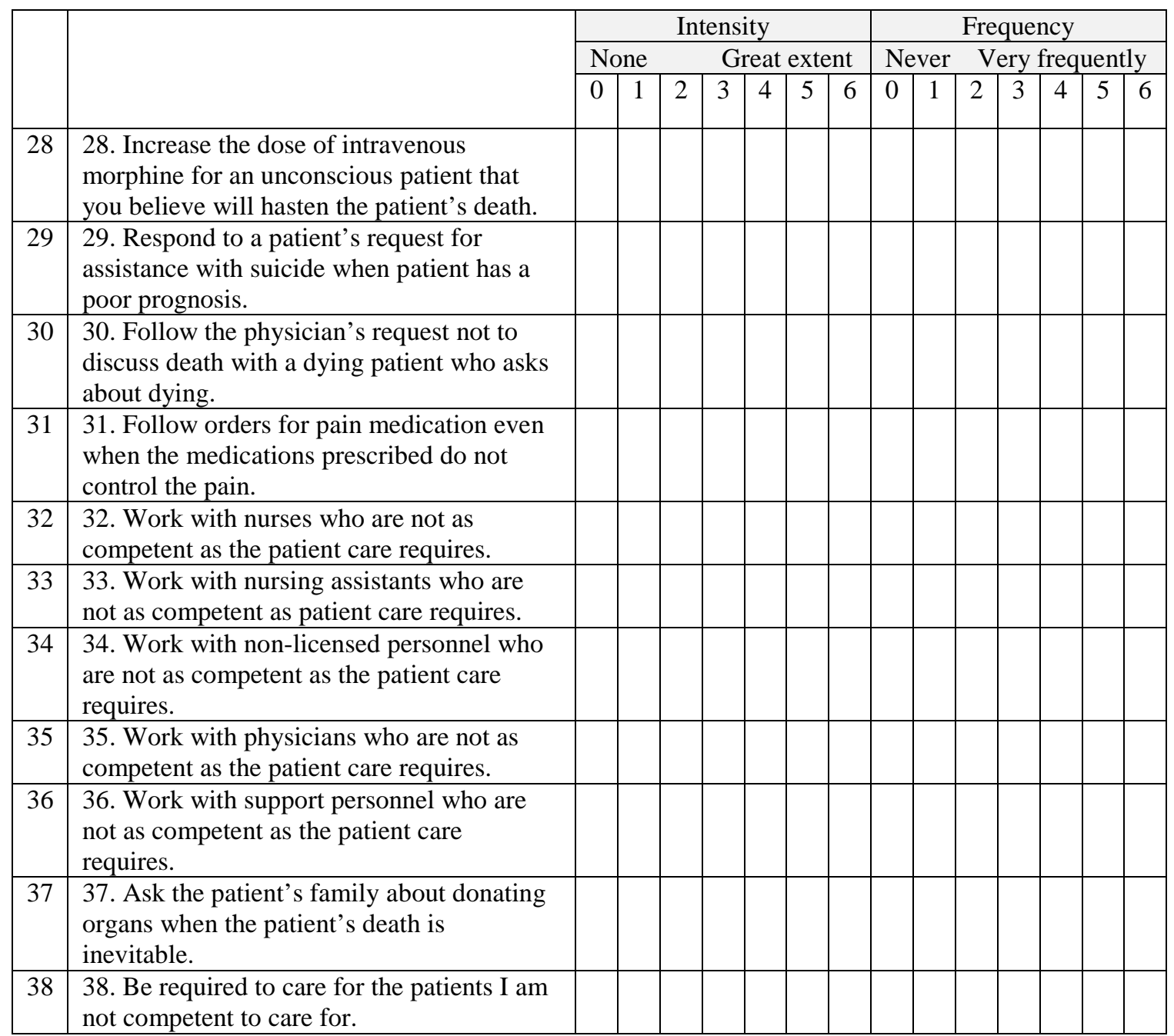

(Taken from “Moral Distress in Critical Care Nurses," by M. C. Corley, 1995, American Journal of Critical Care, 4, 280-285.) 
APPENDIX B

IMPACT OF EVENT SCALE 
Scale ID:

Directions: Below is a list of comments made by people about stressful life events and the context surrounding them. Read each item and decide how frequently each item was true for you regarding

(Insert stressor event here.)

Please indicate how long ago the event occurred:

Days:______ Weeks________ Months_________ Years

If the item did not occur, choose the NOT AT ALL option. Using the following scale of 0 to 5 , circle the number of the response which best describes that item. Please complete each item.

1. I thought about it when I didn't mean to.

$\underline{\text { Not at }} \underline{\text { Rarely }} \underline{\text { Sometimes }} \quad \underline{\text { Often }}$

2. I avoided letting myself get upset when I $\underline{\text { all }}$ thought about it or was reminded of it.

3. I tried to remove it from memory.

4. I had trouble falling asleep or staying asleep,

$\begin{array}{llllll}0 & 1 & 2 & 3 & 4 & 5\end{array}$

because of pictures or thoughts that came into

my mind.

5. I had waves of strong feelings about it.

6. I had dreams about it.

7. I stayed away from reminders of it.

0

0

2

3

4

8. I felt as if it hadn't happened or wasn't real.

9. I tried not to talk about it.

10. Pictures about it popped into my mind.

$\begin{array}{llllll}0 & 1 & 2 & 3 & 4 & 5 \\ 0 & 1 & 2 & 3 & 4 & 5\end{array}$

11. Others things kept making me think about it.

12. I was aware that I still had a lot of feelings

$\begin{array}{llllll}0 & 1 & 2 & 3 & 4 & 5 \\ 0 & 1 & 2 & 3 & 4 & 5 \\ 0 & 1 & 2 & 3 & 4 & 5 \\ 0 & 1 & 2 & 3 & 4 & 5 \\ 0 & 1 & 2 & 3 & 4 & 5 \\ 0 & 1 & 2 & 3 & 4 & 5 \\ 0 & 1 & 2 & 3 & 4 & 5 \\ 0 & 1 & 2 & 3 & 4 & 5\end{array}$
about it, but I didn't deal with them.

13. I tried not to think about it.

14. Any reminder brought back feelings about it.

15. My feelings about it were kind of numb.

$\begin{array}{llllll}0 & 1 & 2 & 3 & 4 & 5 \\ 0 & 1 & 2 & 3 & 4 & 5 \\ 0 & 1 & 2 & 3 & 4 & 5\end{array}$

(Note that the Avoidance subscale is the average of items 2, 3, 7, 8, 9, 12, 13, 15; the Intrusion subscale is calculated from the remaining items.) 
APPENDIX C

DEMOGRAPHIC DATA FORM 
Please provide the following information. As with your answers to other portions of this survey, your responses will be kept confidential.

1. Gender: Male Female

2. Age:

3. Race/Ethnicity:

Black

Hispanic/Latino

Asian

Caucasian

Pacific Islander

Other (please specify)

4. Highest level of education:

Associate degree in nursing

Diploma degree in nursing

MSN

Bachelor's/BSN

Doctorate

Degree in field other than nursing. Indicate field

5. How many years have you worked as an RN?

Less than 1 year

1-2 years

3-4 years

$5-10$ years

11-15 years
16-20 years

21-25 years

26-30 years

More than 30 years

6. How many years have you worked as an $\mathrm{RN}$ in a critical care setting, if any:

Less than 1 year

1-2 years

3-4 years

$5-10$ years

11-15 years
16-20 years

21-25 years

26-30 years

More than 30 years

Have not worked in a critical care setting

7. Do you currently work in an intensive care/critical care setting?

Yes

No

8. How many years have you worked in your current position?

Less than 1 year

1-2 years

3-4 years

5-10 years
11-15 years

16-20 years

21-25 years

26-30 years

More than 30 years 
9. Is your current position:

Full time (36+ hours/week)

Part time

Per Diem/Casual

10. What state do you work in? 
APPENDIX D

PERMISSIONS 


\title{
Permission to Use the Moral Distress Scale
}

\author{
Mary C Corley/FS/VCU [mccorley@vcu.edu] \\ Sent: $\quad$ Saturday, June 13, 2009 9:17 AM \\ To: M \\ Cc: $\quad M$ \\ DeVillers, Mary Jo \\ $\mathrm{M}$ \\ mccorley@vcu.edu \\ Attachments: 偪] Moral Distress
}

To Mary Jo DeVillers:

You have my permission to use either version of the Moral Distress Scale for your dissertation research. Please share your findings with me.

Thank you,

Mary C. Corley, PhD, RN

Associate Professor, Emeritus

Virginia Commonwealth University

School of Nursing

Richmond, VA 23298=05 


\title{
RE: Impact of Event Scale
}

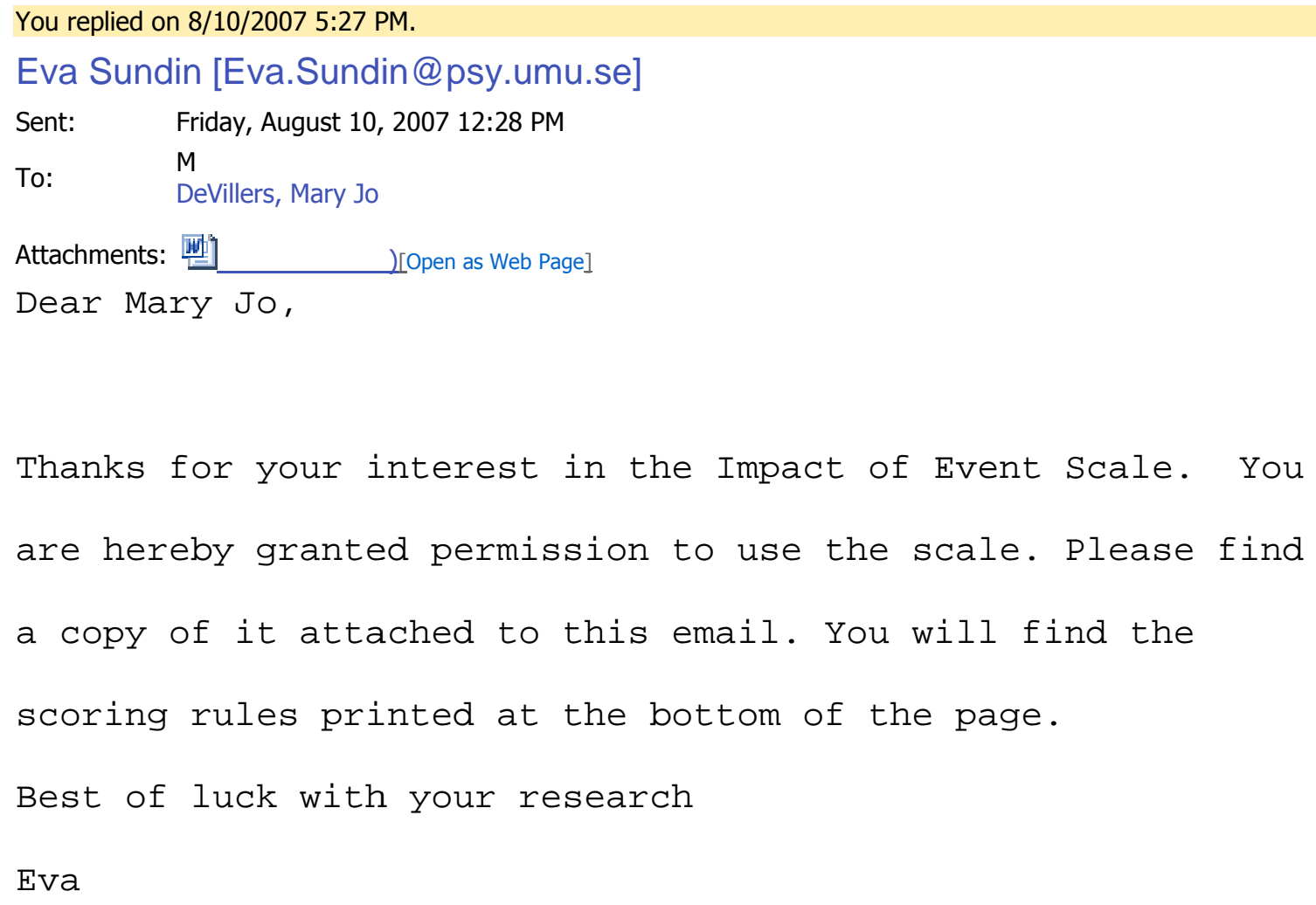

Thanks for your interest in the Impact of Event Scale. You are hereby granted permission to use the scale. Please find a copy of it attached to this email. You will find the scoring rules printed at the bottom of the page. Best of luck with your research

Eva

\author{
Eva Sundin, Ph.D., Reader \\ Department of Psychology \\ Umeå University \\ SE-901 87 Umeå, Sweden \\ Phone: +46 (0) 907866629 \\ Fax: +46 (0) 907866695 \\ email: eva.sundin@psy.umu.se
}




\section{REFERENCES}

Almonte, A. L. C. (2009). Humanitarian nursing challenges: A grounded theory study. Military Medicine, 174(5), 479-485.

American Nurses Association. (2001). Code of ethics for nurses. Silver Spring, MD: American Nurses Association.

Austin, W., Lemermeyer, G., Goldberg, L., Bergum, V., \& Johnson, M. S. (2005a). Moral distress in healthcare practice: The situation of nurses. HEC Forum: An Interdisciplinary Journal on Hospitals' Ethical and Legal Issues, 17(1), 33-48.

Austin, W., Rankel, M., Kagan, L., Bergum, V., \& Lemermeyer, G. (2005b). To stay or to go, to speak or stay silent, to act or not to act: Moral distress as experienced by psychologists. Ethics \& Behavior, 15(3), 197-212.

Bratt, M. M. (2009). Retaining the next generation of nurses: The Wisconsin nurse residency program provides a continuum of support. The Journal of Continuing Education in Nursing, 40(9), 416-425.

Brosche, T. A. (2007). A grief team within a healthcare system. Dimensions of Critical Care Nursing, 26(1), 21-28.

Buchan, J., \& Aiken, L. (2008). Solving nursing shortages: A common priority. Journal of Clinical Nursing, 17(24), 3262-3268.

Buerhaus, P. I. (2009). The shape of recovery: Economic implications for the nursing workforce. Nursing Economic\$, 27(5), 336, 338-340.

Carpenter, C. (2005). Dilemmas of practice as experienced by physical therapists in rehabilitation settings. Physiotherapy Canada, 57(1), 63-76.

Cohen, J. (1969). Statistical power analysis for the behavioral sciences. New York: Academic Press, Inc.

Corley, M. C. (1995). Moral distress of critical care nurses. American Journal of Critical Care, 4(4), 280-285.

Corley, M. C. (2002). Nurse moral distress: A proposed theory and research agenda. Nursing Ethics, 9(6), 636-650. 
Corley, M. C., Elswick, R. K., Gorman, M., \& Clor, T. (2001). Development and evaluation of a moral distress scale. Journal of Advanced Nursing, 33(2), 250256.

Corley, M. C., Minick, P., Elswick, R. K., \& Jacobs, M. (2005). Nurse moral distress and ethical work environment. Nursing Ethics, 12(4), 381-390.

Davis, B. A., Burns, J., Rezac, D., Dillard, B., Kieffner, E., Gargus, J. ...Waters, J. (2005). Family stress and advance directives. Journal of Hospice and Palliative Nursing, 7(4), 219-227.

de Raeve L. (1998). Maintaining integrity through clinical supervision. Nursing Ethics, 5(6), 486-496.

Elpern, D. H., Covert, B., \& Kleinpell, R. (2005). Moral distress of staff nurses in a medical intensive care unit. American Journal of Critical Care, 14(6), 523-530.

Fenton, M. (1988). Moral distress in clinical practice: Implications for the nurse administrator. Canadian Journal of Nursing Administration, 1(3), 8-11.

Ferrell, B. R. (2006). Understanding the moral distress of nurses witnessing medically futile care. Oncology Nursing Forum, 33(5), 922-930.

Fogel, K. M. (2007). The relationships of moral distress, ethical climate, and intent to turnover among critical care nurses (Doctoral dissertation). Available from ProQuest Dissertations and Theses database. (UMI No. 3280688)

Førde, R., \& Aasland, O. G. (2008). Moral distress among Norwegian doctors. Journal of Medical Ethics, 34(7), 521-525.

Fry, S. T., Harvey, R. M., Hurley, A. C., \& Foley, B. J. (2002). Development of a model of moral distress in military nursing. Nursing Ethics, 9(4), 373-387.

Gardner, C., Babin, A., Romero, K., Trull, K., \& Turpin, P. G. (2009). S.T.R.O.N.G.:Supporting the retention of new grads. Nursing Management, 40(6), 9-12.

Green, A. E., \& Jeffers, B. R. (2006). Exploring moral distress in the long-term care setting. Perspectives, 30(4), 5-9.

Gutierrez, K. M. (2005). Critical care nurses' perceptions of and responses to moral distress. Dimensions of Critical Care Nursing, 24(5), 229-241. 
Hamric, A. B., \& Blackhall, L. J. (2007). Nurse physician perspectives on the care of dying patients in intensive care units: Collaboration, moral distress, and ethical climate. Critical Care Medicine, 35(2), 422-429.Hanna, D. R. (2004). Moral distress: The state of the science. Research and Theory for Nursing Practice: An International Journal, 18(1), 73-93.

Hanna, D. R. (2005). The lived experience of moral distress: Nurses who assisted with elective abortions. Research and Theory for Nursing Practice: An International Journal, 19(1), 95-124.

Hardingham, L. B. (2004). Integrity and moral residue: Nurses as participants in a moral community. NursingPhilosophy, 5, 127-134.

Healy, C. M., \& McKay, M. F. (2000). Nursing stress: The effects of coping strategies and job satisfaction in a sample of Australian nurses. Journal of Advanced Nursing, 31(3), 681-688.

Hogan, N. S., \& Schmidt, L. A. (2002). Testing the grief to personal growth model using structural equation modeling. Death Studies, 26, 615-634.

Horowitz, M. J., Field, N. P., Zanko, A., Donnelly, E. F. Epstein, C., \& Longo, F. (2001). Psychological impact of news of genetic risk for Huntington disease. American Journal of Medical Genetics, 3, 188-192.

Horowitz, M., Wilner, N., \& Alveraz, W. (1979). Impact of event scale: A measure of subjective stress. Psychosomatic Medicine, 41(3), 209-218.

House, R. J., Rizzo, J. R. (1972). Toward the measurement of organizational practices: Scale development and validation. Journal of Applied Psychology, 56(5), 388396.

Hutchinson, S. (1990). Responsible subversion: A study of rule-bending among nurses. Scholarly Inquiry for Nursing Practice, 4(1), 3-17.

Jameton, A. (1984). Nursing practice: The ethical issues. Englewood Cliffs, NJ: Prentice Hall.

Jameton, A. (1993). Dilemmas of moral distress: Moral responsibility and nursing practice. AWHONN's Clinical Issues in Perinatal and Women's Health Nursing, $4(4), 542-551$. 
Janvier, A., Nadeau, S., Deschênes, M., Couture, E., \& Barrington, K. J. (2007). Moral distress in the neonatal intensive care unit: Caregiver's experience. Journal of Perinatology, 27(4), 203-208.

Kagan, I., Ovadia, K. L., \& Kaneti, T. (2009). Perceived knowledge of blood-borne pathogens and avoidance of contact with infected patients. Journal of Nursing Scholarship, 41(1), 13-19. Kain, V. J. (2007). Moral distress and providing care to dying babies in neonatal nursing. International Journal of Palliative Nursing, 13(5), 243-248.

Kelly, B. (1998). Preserving moral integrity: A follow-up study with new graduate nurses. Journal of Advanced Nursing, 28(5), 1134-1145.

Laabs, C. A. (2005). Moral problems and distress among nurse practitioners in primary care. Journal of the American Academy of Nurse Practitioners, 17(2), 76-84.

Lambert, V. A., Lambert, C. E., \& Ito, M. (2004). Workplace stressors, ways of coping and demographic characteristics as predictors of physical and mental health of Japanese hospital nurses. International Journal of Nursing Studies, 41(1), 85-97.

Lambert, V. A., Lambert, C. E., Petrini, M., Li, X. M., \& Zhang, Y. J. (2007). Predictors of physical and mental health in hospital nurses within the People's Republic of China. International Nursing Review, 54, 85-91.

Lee, B. (2003). K.E.E.P. your nurses for life. Satisfaction Monitor: The Leader in Satisfaction Measurement, Performance, \& Improvement. September/October, 13. Retrieved from http://www.sageteam.com/pdf/SatMon_SepOct03.pdf

Lieberman, M. D. (2000). Intuition: A social cognitive neuroscience approach. Psychological Bulletin, 126(1), 109-137.

Lützén, K., Johansson, A. \& Nordström,G. (2000). Moral sensitivity: Some differences between nurses and physicians. Nursing Ethics, 7(6), 521-530.

Mackintosh, C. (2007). Protecting the self: A descriptive qualitative exploration of how registered nurses cope with working in surgical areas. International Journal of Nursing Studies, 44(6), 982-990.

McDaniel, C. (1995). Organizational culture and ethics work satisfaction. Journal of Nursing Administration, 25(11), 15-21.

Meltzer, L. S., \& Huckabay, L. M. (2004). Critical care nurses' perceptions of futile care and its effect on burnout. American Journal of Critical Care, 13(3), 202-208. 
Millette, B. E. (1993). Client advocacy and the moral orientation of nurses. Western Journal of Nursing Research, 15(5), 607-618.

Mosely, A., Jeffers, L., \& Paterson, J. (2008). The retention of the older nursing workforce: A literature review exploring factors which influence the retention and turnover of older nurses. Contemporary Nurse: A Journal for the Australian Nursing Profession, 30(1), 46-56. Nathaniel, A. K. (2006). Moral reckoning in nursing. Western Journal of Nursing Research, 28(4), 419-438.

Nieswiadomy, R. M. (1998). Foundations of nursing research. Stamford, CT: Appleton \& Lange.

Oddi, L. F., Cassidy, V. R., \& Fisher, C. (1995). Nurses' sensitivity to the ethical aspects of clinical practice. Nursing Ethics, 2(3). 197-209.

O’Haire, S. E., \& Blackford, J. C. (2005). Nurses' moral agency in negotiating parental participation in care. International Journal of Nursing Practice, 11, 250-256.

Olson, L. L. (1998). Hospital nurses' perceptions of the ethical climate of their work setting. Image: Journal of Nursing Scholarship, 30(4), 345-349.

Pallant, J. (2007). SPSS survival manual. New York, NY: Mc Graw Hill.

Penticuff, J. H., \& Walden, M. (2000). Influence of practice environment and nurse characteristics on perinatal nurses' responses to ethical dilemmas. Nursing Research, 49(2), 64-72.

Peter, E., \& Liaschenko, J. (2004). Perils of proximity: A spatiotemporal analysis of moral distress and moral ambiguity. Nursing Inquiry, 11(4), 218-225.

Pijl-Zieber, E., Hagen, B., Armstrong-Esther, C., Hall, B., Akins, L., \& Stingl, M. (2008). Moral distress: An emerging problem for nurses in long-term care? Quality in Ageing, 9(2), 39-48.

Pike, A. (1991). Moral outrage and moral discourse in nurse-physician collaboration. Journal of Professional Nursing, 7, 351-363.

Polit, D. F. (2010). Statistics and data analysis for nursing research. (2 ${ }^{\text {nd }}$ ed.). Upper Saddle River, NJ: Pearson Education.

Polit, D. F., \& Beck, C. T. (2006). Essentials of nursing research: Methods, appraisal, and utilization $\left(6^{\text {th }}\right.$ ed.). Philadelphia: Lippincott Williams and Wilkins. 
Polit, D. F., \& Hungler, B. P. (1999). Nursing research: Principles and methods. Philadelphia: Lippincott.

Redman, B. K., \& Fry, S. T. (2000). Nurses' ethical conflicts: What is really known about them. Nursing Ethics, 7(4), 360-366.

Rest, J. R. (1986). Moral development: Advances in research and theory. New York: Praeger.

Rice, E. M., Rady, M. Y., Hamrick, A., Verheijde, J. L., \& Pendergast, D. K. (2008). Determinants of moral distress in medical and surgical nurses at an adult acute tertiary care hospital. Journal of Nursing Management, 16, 360-373.

Rokeach, M., \& Regan, J. F. (1980). The role of values in the counseling situation. Personnel \& Guidance Journal, 58(9), 576-582.

Röndahl, G., Innala, S., \& Carlsson, M. (2003). Nursing staff and nursing students' attitudes towards HIV-infected and homosexual HIV-infected patients in Sweden and the wish to refrain from nursing. Journal of Advanced Nursing, 41(5), 454461.

Rushton, C. H. (2006). Defining and addressing moral distress. AACN Advanced Critical Care, 17(2), 161-168.

Schluter, J., Winch, S., Holzhauser, K., \& Henderson, A. (2008). Nurses' moral sensitivity and hospital ethical climate: A literature review. Nursing Ethics, 15(3), 304-321.

Schwenzer, K. J., \& Wang, L. (2006). Assessing moral distress in respiratory care practitioners. Critical Care Medicine, 34(12), 2967-2972.

Scott, P. A. (1998). Morally autonomous practice? Advances in Nursing Science, 21(2), 69-79.

Severinsson, E. (2003). Moral stress and burnout: Qualitative content analysis. Nursing and Health Sciences, 5, 59-66.

Siminoff, L. A., Erlen, J. A., \& Sereika, S. (1998). Do nurses avoid AIDS patients? Avoidance behaviors and the quality of care of hospitalized AIDS patients. AIDS Care, 10(2), 147-162.

SPSS forWindows, (Version 17) [Computer software]. Chicago, IL: SPSS Inc. 
Storch, J. L., Rodney, P., Pauly, R., Brown, H., \& Starzomski, R. (2002). Listening to nurses' moral voices: Building a quality health care environment. Canadian Journal of Nursing Leadership, 15(4), 7-16.

Sundin, D., \& Fahy, K. (2008). Critical, post-structural, interpretive interactionism: An update on Denzin's methodology. Nurse Researcher, 16(1), 7-23.

Sundin-Huard, D., \& Fahy, K. (1999). Moral distress, advocacy and burnout: Theorizing the relationships. International Journal of Nursing Practice, 5, 8-13.

Sundin, E. C., \& Horowitz, M. J. (2002). Impact of Event Scale: Psychometric properties. British Journal of Psychiatry, 180, 205-209.

Sundin, E. C., \& Horowitz, M. J. ((2003). Horowitz's Impact of Event Scale evaluation of 20 years of use. Psychosomatic Medicine, 65(5), 870-876.

Taylor, S. (2002). Moral fatigue-A nursing perspective. Bioethics Forum, 18(1/2), 3743.

Tiedje, L. B. (2000). Moral distress in perinatal nursing. Journal of Perinatal \& Neonatal Nursing, 14(2), 36-43.

Tourangeau, A. E., Cummings, G., Cranley, L. A., Ferron, E. M., \& Harvey, S. (2010). Determinants of hospital nurse intention to remain employed: Broadening our understanding. Journal of Advanced Nursing, 66(1), 22-32.

Tourtillott, E. (1982). Commitment-a lost characteristic. New York: National League for Nursing.

Tyson, P. D., \& Pongruengphant, R. (1996). Avoidance as a coping strategy for nurses in Thailand. Psychological Reports, 79(2), 592-594.

Tyson, P. D., Pongruengphant, R., \& Aggarwal, B. (2002). Coping with organizational stress among hospital nurses in Southern Ontario. International Journal of Nursing Studies, 39(4), 453-459.

University of Wisconsin System. (2010). Qualtrics ${ }^{\mathrm{TM}}$ [Survey]. Provo, UT. Available at http://www.qualtrics.com/

U.S. Department of Health and Human Services, Health Resources and Services Administration. (n.d.). The registered nurse population: Findings from the 2004 national sample survey of registered nurses. Retrieved from http://bhpr.hrsa.gov/healthworkforce/rnsurvey04/appendixa.htm. 
U.S. Department of Health and Human Services, Health Resources and Services Administration. (2010). The registered nurse population: Initial findings from the 2008 national sample survey of registered nurses. Retrieved from http://bhpr.hrsa.gov/healthworkforce/rnsurvey/initialfindings2008.pdf

Webster, G.C. \& Baylis, F.E. (2000). Moral residue. In S.R. Rubin \& L. Zoloth (Eds.). Margin of error: The ethics of mistakes in the practice of medicine (pp. 217-230. Hagerstown, MD: University Publishing Group.

Wilkinson, J. M. (1987/88). Moral distress in nursing practice: Experience and effect. Nursing Forum, 23(1), 16-29.

Wong, D. F. K., Leung, S. S. K., \& So, C. K. O. (2001). Differential impacts of coping strategies on the mental health of Chinese nurses in hospitals in Hong Kong. International Journal of Nursing Practice, 7(3), 188-198.

Wurzbach, M. E. (1996). Long-term care nurses' ethical convictions about tube feeding. Western Journal of Nursing Research, 18(1), 63-76.

Zuzelo, P. R. (2007). Exploring the moral distress of registered nurses. Nursing Ethics, 14(3), 344-359. 
VITA

Mary Jo De Villers was born in Green Bay, Wisconsin. Before attending Loyola University Chicago, she attended the University of Minnesota, Minneapolis, where she earned a Master of Science in Nursing with a Nursing Education focus in 2001. Currently, Mary Jo is Assistant Professor of Nursing at the University of Wisconsin, Green Bay. 


\section{DISSERTATION APPROVAL SHEET}

The dissertation submitted by Mary Jo De Villers has been read and approved by the following committee:

Holli A. DeVon, Ph.D., Director

Associate Professor

Loyola University Chicago

Beverly Kopala, Ph.D.

Associate Professor

Loyola University Chicago

Karen L. Saban, Ph.D.

Assistant Professor

Loyola University Chicago

The final copies have been examined by the director of the dissertation and the signature which appears below verifies the fact that any necessary changes have been incorporated and that the dissertation is now given final approval by the committee with reference to content and form.

The dissertation is therefore accepted in partial fulfillment of the requirements for the degree of Doctor of Philosophy. 